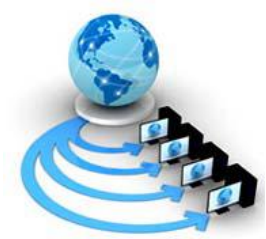

Volume 10, No. 4, July - August 2019

ISSN No. 0976-5697

International Journal of Advanced Research in Computer Science

RESEARCH PAPER

Available Online at www.ijarcs.info

\title{
AN ANALYSIS OF VARIOUS FUNCTION IN WIRELESS SENSOR NETWORK APPLIED IN PRECISION AGRICULTURE
}

\author{
Avishek Jana \\ Department of Computer Science \& Application, \\ Prabhat Kumar College, \\ Contai, PurbaMedinipur, \\ West Bengal, India
}

\author{
Arindam Roy*, Corresponding Author \\ Department of Computer Science \& Application, \\ Prabhat Kumar College, \\ Contai, PurbaMedinipur, \\ West Bengal, India
}

\begin{abstract}
Precision Agriculture is the idea of instantaneous observation of environmental and field parameters like soil moisture, humidity, temperature, soil PH etc. and transfer of the values of those parameters to the remote central server, which on the basis of these values, takes appropriate action to control the use of different resources like pesticides, water, fertilizer etc. in an optimized way in order to maximize the crop yield in terms of both quality and quantity. In Precision Agriculture, the farmers monitor and analyze the values of the field parameters in real time by using the Wireless Sensor Network (WSN) technology with the help of a varied range of sensors. This information further helps in making the exact judgment for controlling the resource allocation. This survey paper explores different existing methods, communication technologies and protocols related to sensor-based data collection, monitoring and control system. It also reviews the application of WSN in Precision Agriculture environment and successfully points out the future scope of the work in this domain.
\end{abstract}

Keywords: Precision Agriculture, Wireless Sensor Network, Wireless Communication Technology, Real time monitoring and control, Resource allocation.

\section{INTRODUCTION}

The main strength of India's economic development is measured by the agricultural growth and development. In upcoming years' old-fashioned way of farming will not be able to solve the problem of ever-increasing demands for the increasing population. Newer techniques need to be adopted to increase the agricultural productivity [1]. It is also important to develop eco-friendly technologies in a sustainable way. The application of WSN technology can be highly beneficial for remote measurement of parameters such as plant growth condition, including temperature, humidity, atmospheric pressure, soil moisture and water level. The wireless monitoring and controlling system can enhance the crop quality and productivity [2, 3]. The technological advancement in agricultural field gives birth to a new concept called precision agriculture (PA). PA is mainly based on the two types of techniques, which are "Map Based Precision Agriculture" \& "Sensor Based Precision Agriculture". On Map Based Precision Agriculture, various techniques like Geographic Information System (GIS), Global Positioning System(GPS), Remote Server (RS) technology, Soil sampling etc. are used to observe and control field parameters. GPS recognizes the exact location of the field, which will be helpful for observing, \& controlling WSN based systems [4]. GIS technology helps us to collect the remotely sensed data, report of the crop inspection, soil survey maps and soil nutrient levels that are stored layer wise in remote central server [5]. However, the main disadvantage is that we cannot get the real time information from a map-based PA Techniques. In this approach, the prescribed map is stored on the server and accessed when required. So, in the meantime, if any changes occur in field variables, then it cannot be fetched. To overcome this problem, sensor-
basedPA techniques can be used where we can get real time data. The Sensor is a device that can sense different types of physical parameters. Various sensor nodes are used to sense environmental and field variables. A simple sensor network consists of micro-controller, memory, analog to digital converter, transceiver \& sensors, which arecapable of collecting sensory information, performing some kind of processing and communicating with other connected nodes in the network [2]. Sensor Network can be deployed for a wide range of applications. Currently its application has increased in agronomy. Observing crops for identifying environmental \& field conditions and detecting the diseases also play an important role in successful farming. WSN technology can help us to decrease the work force, effort and time required for observing an agricultural environment. The application of WSN for crop field monitoring \& controlling of resource utilization offers a tremendous possibility for massive profits for the farmers and society as a group [5].This survey paper reviews the existing works, finds their weaknesses and explores the scope of the future work in this field.

\section{WIRELESS SENSOR NETWORK FOR PRECISION AGRICULTURE (PA)}

The Wireless Sensor Network (WSN) consists of distributed autonomous sensors to observe and control field \& environmental parameters. It then submits the data to the remote server through the gateway node. The availability of smarter, smaller and inexpensive sensors solves the problem of monitoring of environmental parameters. The wireless sensors, connected with the applications, work in collaboration with the Wireless Node.

In the early days, monitoring system depended heavily on the sample collection of the field parameters and laboratory analysis. Therefore, it was impossible to retrieve and 
analyze the data in real-time. With the advancement of technology, monitoring \& controlling system have upgraded from off-line sensors to real time operational sensor network. Consequently, WSN is applied for retrieving, loading and sharing the data. The data are collected from the various types of sensors. Group of sensor nodes and a communication system that permits spontaneous data collection and sharing defines a WSN system. It permits to observe any small change in the environmental and field parameters and provide the appropriate warning accordingly.

The Wireless Sensor Node consists of various types of sensors, analyzing \& the transmission module with a GPS system and power units. These nodes are efficiently positioned either inthe node mapping area or very near to it [22].

A WSN is a spatially distributed network of comparatively small, low-weight wireless nodes that are equipped with large number of sensors. A typical node is made of a transceiver, sensor(s), storage and power source. Figure 1 shows the simple architecture of the WSN nodes. The node has the capability to sense, analyze and share spatial and temporal variables, which are retrieved from environment \& agriculture field.

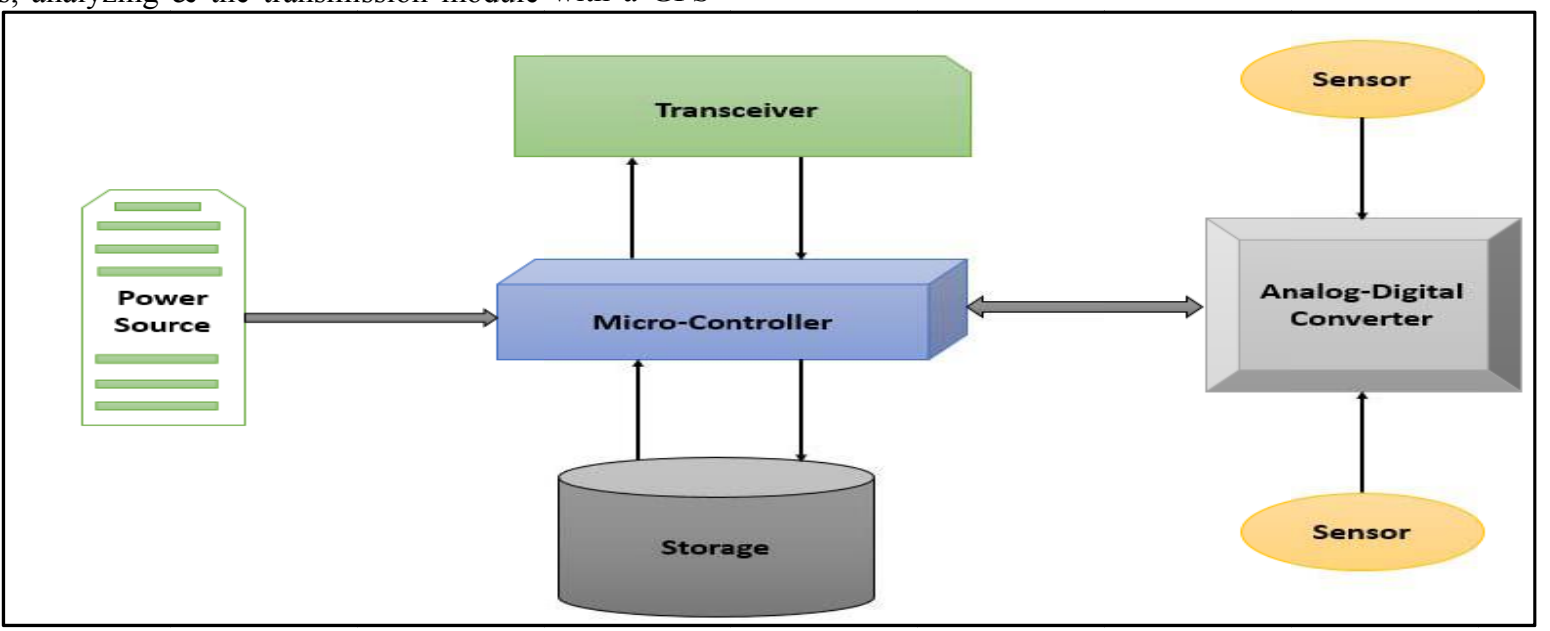

Fig. 1: Basic Architecture of Wireless Sensor Node

\section{WSN TOPOLOGIES}

In the area of Precision Agriculture, WSN topologies are classified into three classes. - Star single-hop topology, Cluster tree-based multiple-hop topology and Mesh topology.

\subsection{Star single-hop topology}

In this type of topology, one node sends data packets to another node through a central hub/server, which is called the Base Station. Instead of sending the packet directly to the destination node, each Sensor Node (SN) sends its packet to the Central Server (CS). Thereafter, according to the requirement, CS transmits the packet to the other node.
Tongtonget. al. [24] suggested a method of sensing and observing the temperature and humidity in a greenhouse environment. The environment is comprised of some sensor nodes, one main node (Gateway), PC Terminal (Central Server), database, web service and one real time warning system. In this system, the temperature and humidity parameters of the greenhouse environment can be sensed and monitored by the sensor node. It then transmits the sensed data to PC terminal. In PC terminal, the database and web service record the sensed values of the parameters at specific times. Finally, the web server draws a curve according to the changing values of the variables. If the curve depicts any anomalous changes, then the warning system is activated, which instructs the user to take proper action. 

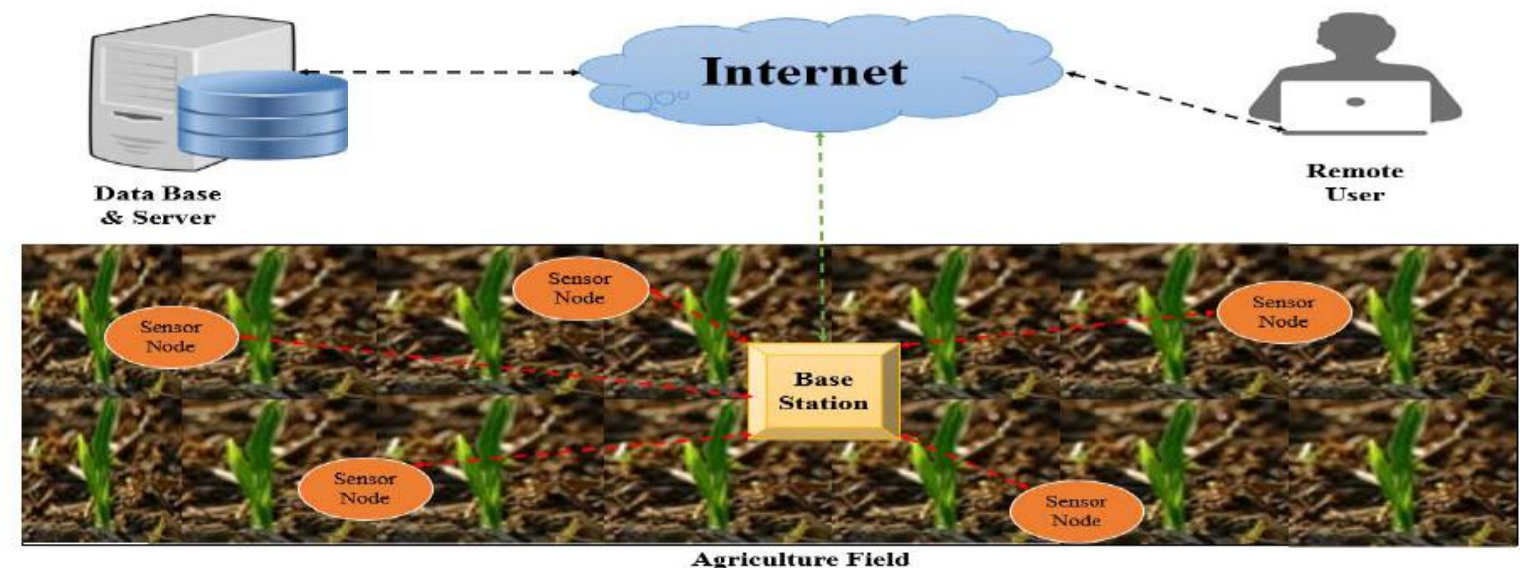

Fig. 2: Star Single-Hop Topology

Shaikh et. al. [25] proposed an irrigation control system to maintain the moisture level of the field for enhancing the crop productivity. By using WSN nodes, the system is designed. The nodes are classified into sensor, actuator and sink nodes. By using ZigBee wireless technology, the system transmits data packets to a connected PC through a serial interface. A star single-hop topology is used in this system. The system also used a broadcast protocol,"ProtoSense" to communicate among the nodes.

\subsection{Cluster tree-based multiple-hop topology}

It is a three-layer, multi-hop topology consisting of a central server named as 'central node' and two or more-star networks. Upper layer contains super cluster head, middle layer consists of cluster head and the lower layer contains terminal nodes. Among those terminal nodes, one of the nodes is selected as a cluster head in that layer. Since the range of the sensor nodes is limited, each of the sensor nodes transmits data to the central node through the nearby cluster head. To transmit data into a super cluster head or a central node, the lower level cluster head act as a repeater to enhance the quality of data packets. This type of network topology diminishes the energy consumption in the WSN deployment.
NesaSudha et al. [26] arranged sensor nodes into three clusters. Each cluster contained six sensor nodes. Among those sensor nodes, one node acted as the gateway and another node was the base station (BS). The data were transmitted to the BS through the cluster heads. Each node transmitted the data packet to the nearby nodes based on single-hop topology. The overall deployment of sensor nodes was based on a cluster tree-based multiple hop topology. Each node was identified through a unique ID, which is known to the BS. According to the Time division multiple Access (TDMA) scheduling, BS selected any one of the nodes as the cluster head at any point of time and broadcasted this information to all of the nodes in the cluster. TDMA scheduler assigned the time slots for each node and those sensor nodes turned ON/OFF according to the schedule to save energy. If the collected data was less than the threshold value, the BS would inform the controller. In this paper, based on TDMA scheduling two methods were used. The first one was a direct communication method, in which each node transmitted the data directly to the sink. The second method used data aggregation method in which nodes were grouped into clusters to save energy. This method saved $10 \%$ energy.
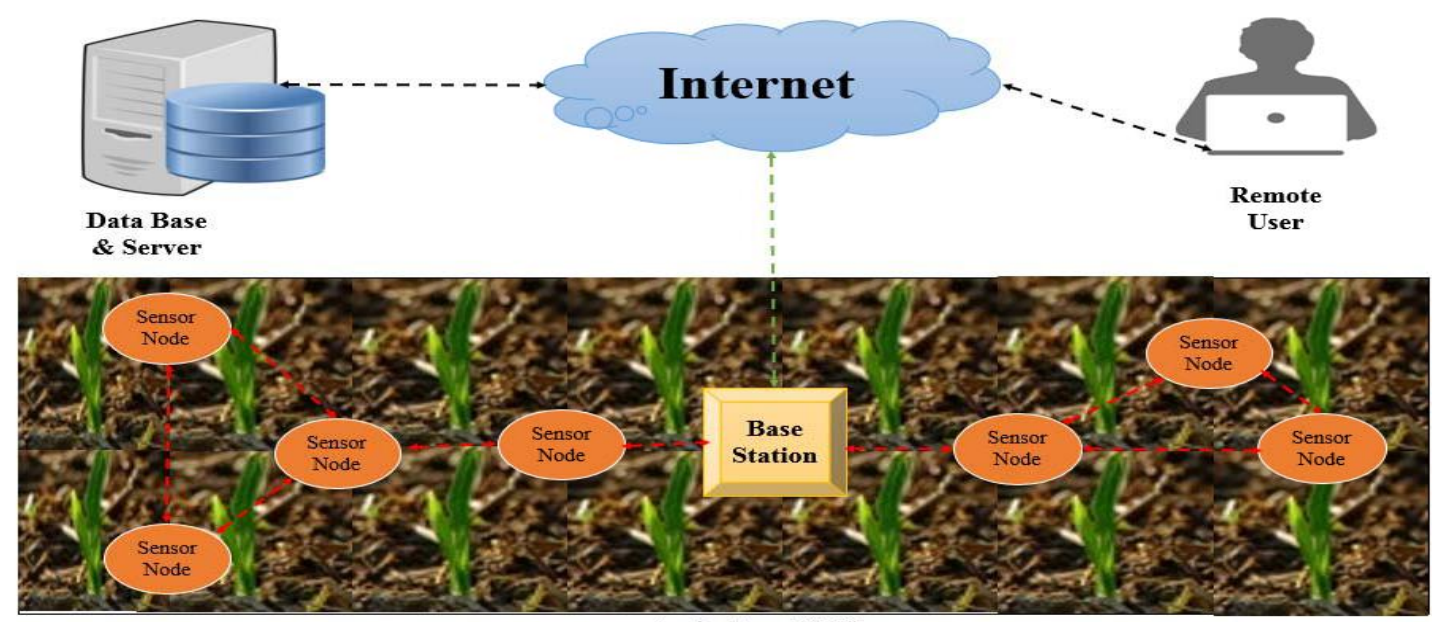

Agriculture Field

Fig. 3: Cluster Tree-based Multi-Hop Topology 


\section{3}

Mesh topology

In mesh topology, each sensor node not only communicates to every other sensor node, but also acts as a relay to transmit data from the other nodes in the network.

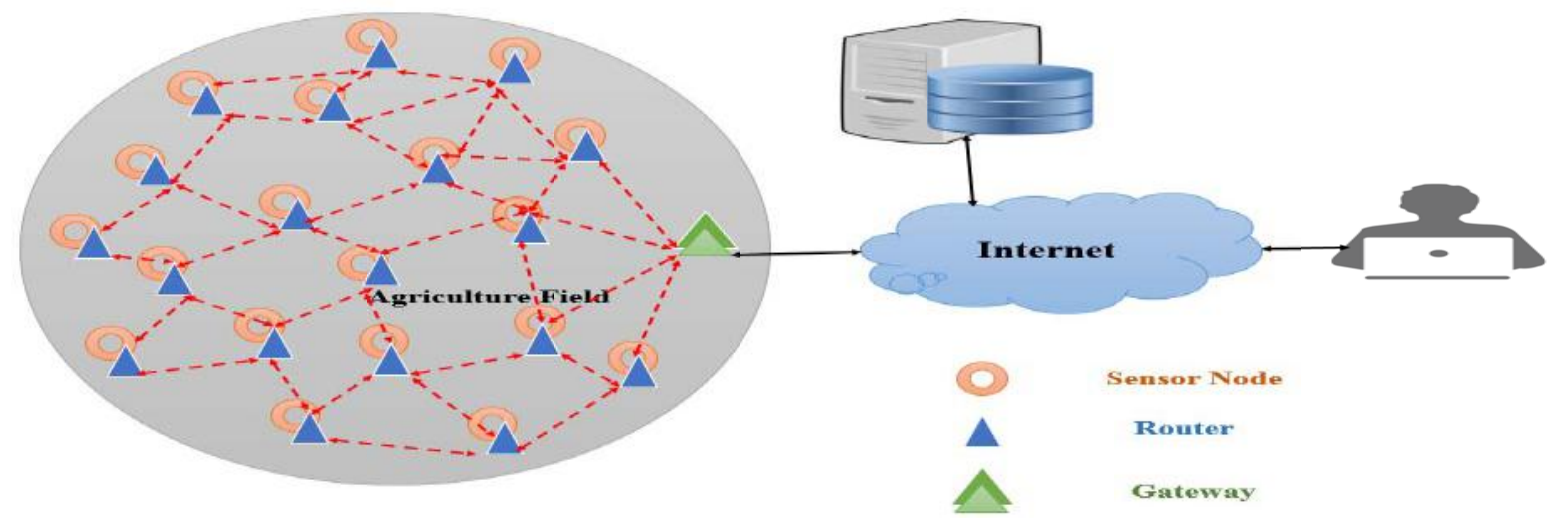

Fig. 4: Mesh Topology

Gao et. al. [27] designed a smart irrigation control system based on WSN. The system was controlled according to the fuzzy logic. The smart control system solved the problems of soil fertility loss and water wastage in irrigation. The ZigBee network was adopted in the mesh network configuration. The system was designed by using sensor nodes and the controller node. Sensor node consisted of soilwet sensors, irrigation pipes, spray irrigation and irrigation control valves. The sensor nodes act as terminal nodes within the cluster. Some sensor nodes also act as routers. These router nodes collect data from the terminal nodes and transmit them to a head node. Head node gathers data from other nodes also. Data is logged at fixed time intervals, analyzed and accordingly the command is transmitted from the controller section for opening and closing the valve.
According to the requirement of water, the control valve opened and closed to maintain the water level of the field.

\subsection{Comparison of Wireless Technology}

The WSN topologies used in the reviewed articles are summarized in Table 1. The table contains the references of the corresponding articles and topology addressed in these papers. From this comparison table it can be concluded that most of the reviewed literatures used Mesh topology to implement WSN in field scale. In mesh topology, each node is connected to all other nodes and thus ensures the reliability of data transmission. Moreover, it can also handle high amounts of data traffic. All the benefits of mesh topology make it popular in WSN based PA application.

Table 1: Comparison of Reviewed literature according to Topology Considered

\begin{tabular}{|c|c|c|c|}
\hline Reference & Star Single-hop Topology & $\begin{array}{c}\text { Cluster Tree Based Multi- } \\
\text { hop Topology }\end{array}$ & Mesh Topology \\
\hline$[24],[25],[30]$ & $\sqrt{ }$ & $\mathrm{X}$ & $\mathrm{X}$ \\
\hline$[26],[31]$ & $\mathrm{X}$ & $\sqrt{ }$ & $\mathrm{X}$ \\
\hline$[27],[32],[33],[34]$ & $\mathrm{X}$ & $\mathrm{X}$ & $\sqrt{ }$ \\
\hline
\end{tabular}

\section{WIRELESS COMMUNICATION TECHNOLOGY}

In Wireless Sensor Network, several communication techniques and protocols are used. In the field, many sensor nodes are deployed. A node is an embedded device with Arduino Board, sensors (Humidity, Moisture, and Temperature, etc.), ZigBee/XBee/Bluetooth/Radio Frequency devices, battery, etc. Sensors are used to retrieve data from the field depending upon various factors. ZigBee/XBee/Bluetooth/Radio Frequency devices are used to communicate among the node and the gateway device. Arduino Board is used to connect sensors and Zigbee/XBee and program is loaded within this micro controller on the basis of which, sensors will work. Nodes are connected through Gateway, which in turn is connected to the base station. The retrieved data are stored in the base station and user (Farmer, Admin, and Agriculture Expert) can access these data through software. If anytime any error condition occurs, then the base station sends the message to the user through the cellular network by using GSM Module so that the users can take steps for solving the problem [18, 20]. Different types of communication technologies and protocols are described in this section.

\subsection{Wi-Fi based Wireless Sensor Network}

A Wireless LAN is one of the important communication technologies used0 in smart agricultural system. A Wi-Fi 
based smart wireless network (Fig. 5) consists of sensor nodes (WSN802G), gateway (wireless router), remote user and server with the database. The sensor nodes connect to the gateway through standard $802.11 \mathrm{~b} / \mathrm{g} / \mathrm{n}$ protocol $[10,25]$. In a first time, authentication of the sensors is done with a standard WPA2-PSK protocol in the gateway $[10,18]$. The gateway is further connected with the internet. The collected data are stored in remote server over the internet. User can access the data from the server through the internet.

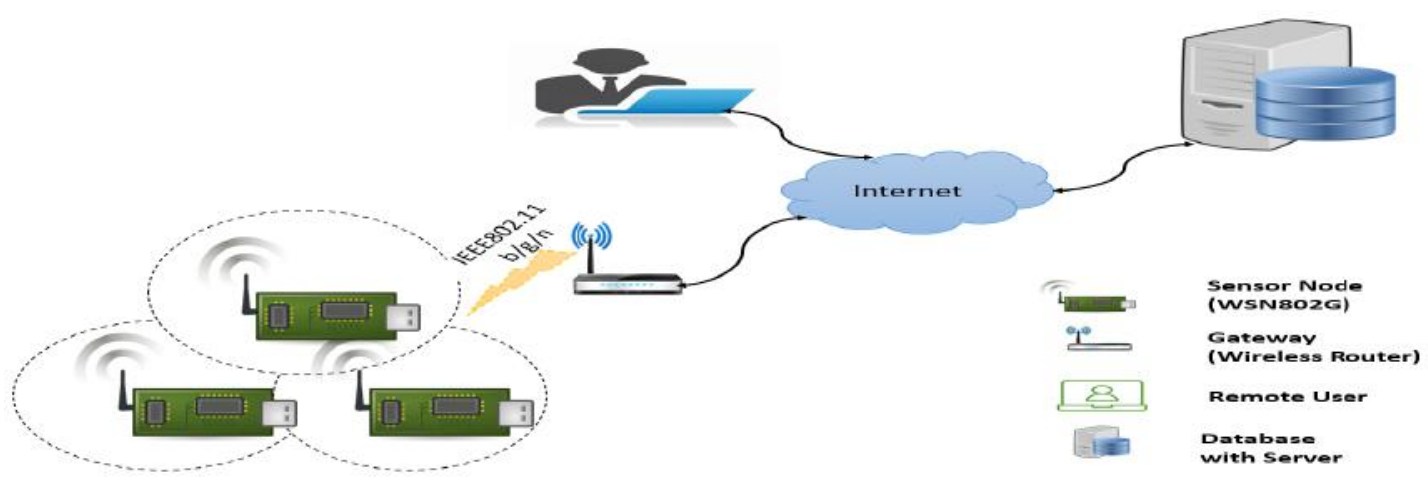

Fig. 5: Wi-Fi based Wirweless Sensor network

This wireless technology [1] helps in real time monitoring of the agricultural field. The field and environmental parameters like water level, temperature, light, atmospheric pressure, humidity, etc. are collected dynamically and stored in server for further processing. The parameters are analyzed in the server to take farm management decisions about resource utilization. Proper decision helps to increase productivity and quality. The sensing modules used in this system can help to increase the battery life cycle as it uses low power (3.0 to $3.63 \mathrm{v}$ ) sensor for data collection.

\subsection{Bluetooth Based Wireless Sensor Network}

Wi-Fi based distributed wireless sensor network has some disadvantages like costly hardware for communication technology, time consuming installation and difficulties in maintenance. To overcome these disadvantages,Bluetooth based WSN can be used in PA. Bluetooth based system (Fig. 6) ensures dynamic, cost effective re-location and low power consumption $[11,22,24]$.

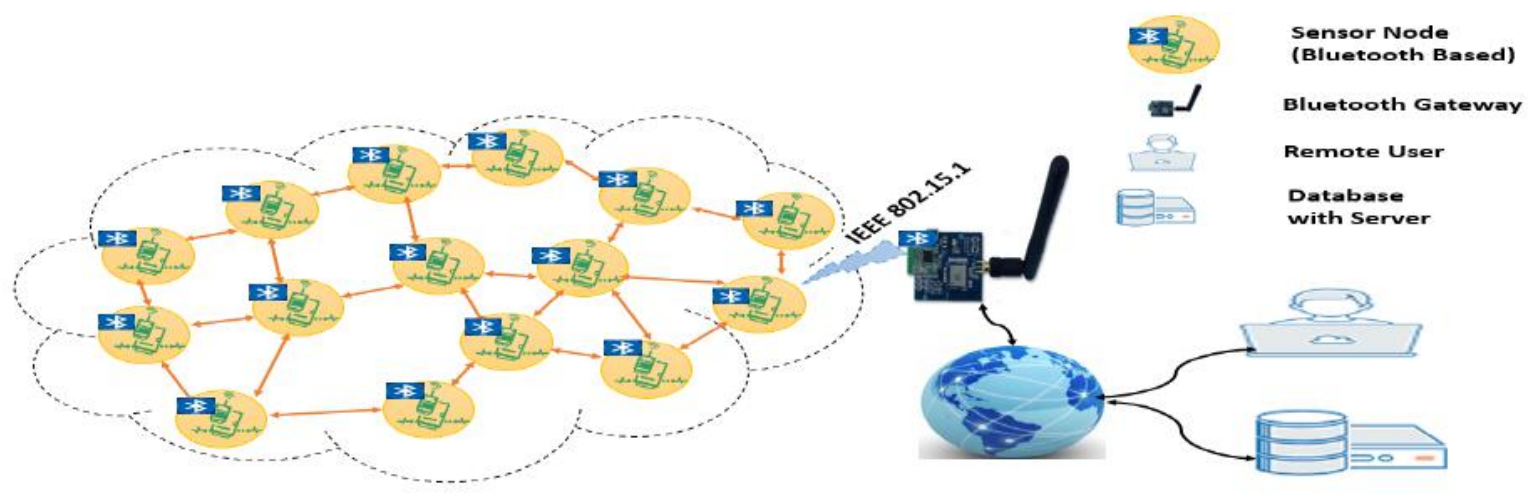

Fig. 6:Bluetooth Based Wireless Sensor Network

A Bluetooth based WSN consists of sensor nodes, gateway, server and remote users. The sensing nodes are distributed over the field in an ad-hoc manner to collect data. Each node has three parts like memory for data logging, communication unit and battery. These nodes transfer data to the gateway node using Bluetooth (IEEE 802.15.1) at 2.4 $\mathrm{GHz}$ frequency. Further data are transferred to the base station (server) through the internet. The necessary analysis and decisions are made at the base station to monitor the environmental and field conditions [3]. The power consumption of this module is low as Bluetooth consumes very low power for transmission. The system is cost effective as Bluetooth is a low-priced technology [5]. But it suffers from low communication range and poor data security.

\subsection{Radio Frequency Based Wireless Sensor Network}

Another important wireless communication technology used in PA is Radio Frequency (RF) based WSN [16, 26]. An architecture of radio frequency based WSN is given in Fig. 7. The architecture has four main parts - sensor nodes, gateway, server and remote users. The sensor nodes connect to the gateway through the RF communication module. Gateway is connected to the server over the internet. The 
remote user communicate with the system using internet connection. Data collection is an important part of PA. Sensor nodes collect the data and transfer to the server through the gateway. The decisions about crop and field management are taken based on the collected data in the server module.. The decisions are sent to the controlling unit through the RF link. Precise control decisions help to increase the productivity.
The communication range of RF technology[21] is $1500 \mathrm{~m}$ and frequency range is $2.4 \mathrm{GHz}$. It consumes very low power. The battery life of each sensor node is 5 months with $2200 \mathrm{mAh}$ at $3.3 \mathrm{v}$ battery. The protocol used in RF technology is IEEE 802.11. The transmission techniques used in this protocol are Frequency Hopping Spread Spectrum (FHSS), Direct Sequence Spread Spectrum(DSSS), and Diffuse Infrared. RF technology is a low-priced technology, which consumes very low power.

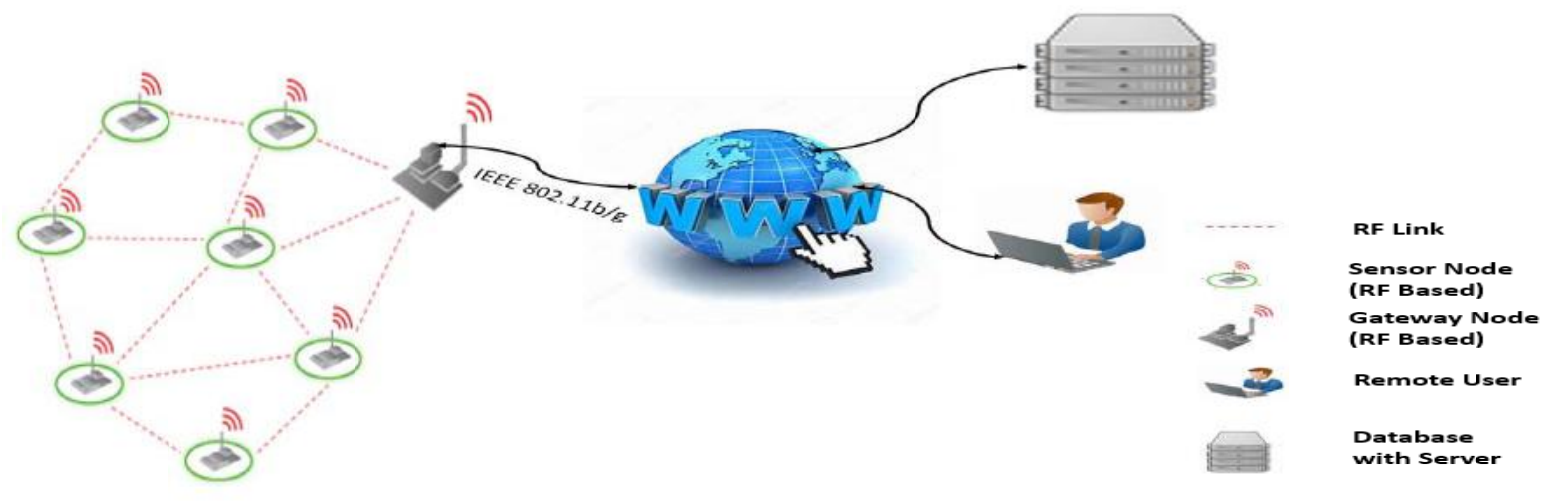

Fig. 7:Radio Frequency Based Wireless Sensor Network

\subsection{Zigbee Based Wireless Sensor Network}

Zigbee (IEEE 802.15.14) is a high level communication protocol for small scale application. Zigbee[27] operates in $2.4 \mathrm{GHz}$ frequency and provides transmission speed 250 $\mathrm{kBs}$ over a range of 10 to $100 \mathrm{~m}$. The architecture of a Zigbee based smart agricultural monitoring system [23] is shown in Fig. 8. The sensors can be configured according to the star, mesh or peer to peer topologies to collect data. The data are sent to the gateway using the Zigbee network. The Gateway sends these data to the server for analysis and decision making. The authenticated user can access these data over the internet from the server. The rate of power consumption is comparatively higher. Moreover, Zigbee is costly with respect to Wi-Fi, Bluetooth and RF technology.

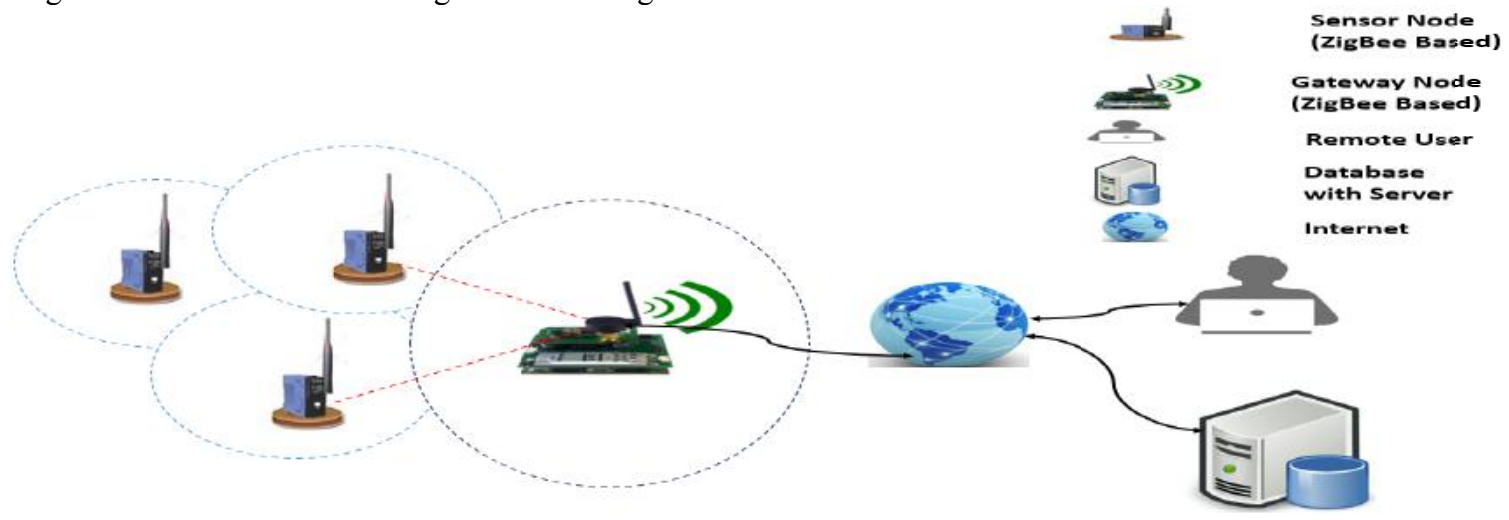

Fig. 8: Zigbee Based Wireless Sensor Network

\subsection{Comparison of Communication Technology}

This section highlights the benefits and limitations of communication technologies used in PA field. Most of the literatures used $\mathrm{Wi}-\mathrm{Fi}$ and Bluetooth for field data transmission, as these two technologies are easily available. The limitation of these two technologies encourages the researcher to use RF device and ZigBee for wireless communication. But ZigBee is very costly. So, RF device can be used for wireless communication in PA field. As the numbers of sensing module arefixed for a particular field, network configuration needs to be done at the beginning of the data collection. This assumption helps to overcome the limitation in RF technology. The comparison table (Table 2) shows that there are very few works done on data collection using this technology. So, there is a large scope of research of using this technology in PA. 
Table 2: Comparison of Communication Technology

\begin{tabular}{|c|c|c|c|}
\hline $\begin{array}{c}\text { Communication } \\
\text { Technology }\end{array}$ & Benefits & Limitation & Reference \\
\hline Wi-Fi & $\begin{array}{c}\text { Easy to configuration, secure data } \\
\text { transmission }\end{array}$ & Short battery life & {$[1,10,18,24,28]$} \\
\hline Bluetooth & $\begin{array}{c}\text { Low cost with low power } \\
\text { consumption. }\end{array}$ & $\begin{array}{c}\text { Limited communication } \\
\text { range }\end{array}$ & {$[3,5,11,22,25]$} \\
\hline Radio Frequency & $\begin{array}{c}\text { Long communication range with low } \\
\text { power consumption. }\end{array}$ & $\begin{array}{c}\text { Reconfiguration Problem } \\
\text { with adding new node }\end{array}$ & {$[16,21,26]$} \\
\hline ZigBee & $\begin{array}{c}\text { configured according to star, mesh } \\
\text { or peer to peer topologies. }\end{array}$ & $\begin{array}{c}\text { Short battery life with high } \\
\text { cost }\end{array}$ & {$[23,27]$} \\
\hline
\end{tabular}

\section{LITERATURE REVIEW}

In 2012, Mandez et al. [1] designed a Wi-Fi based monitoring system for agriculture field. The system architecture has been shown in Fig. 9. The system collected environmental temperature, humidity, light intensity, pressure, and soil moisture and field water level. These data are transmitted to a central server through the WSN802G Wi-Fi module. The interconnected sensing nodes

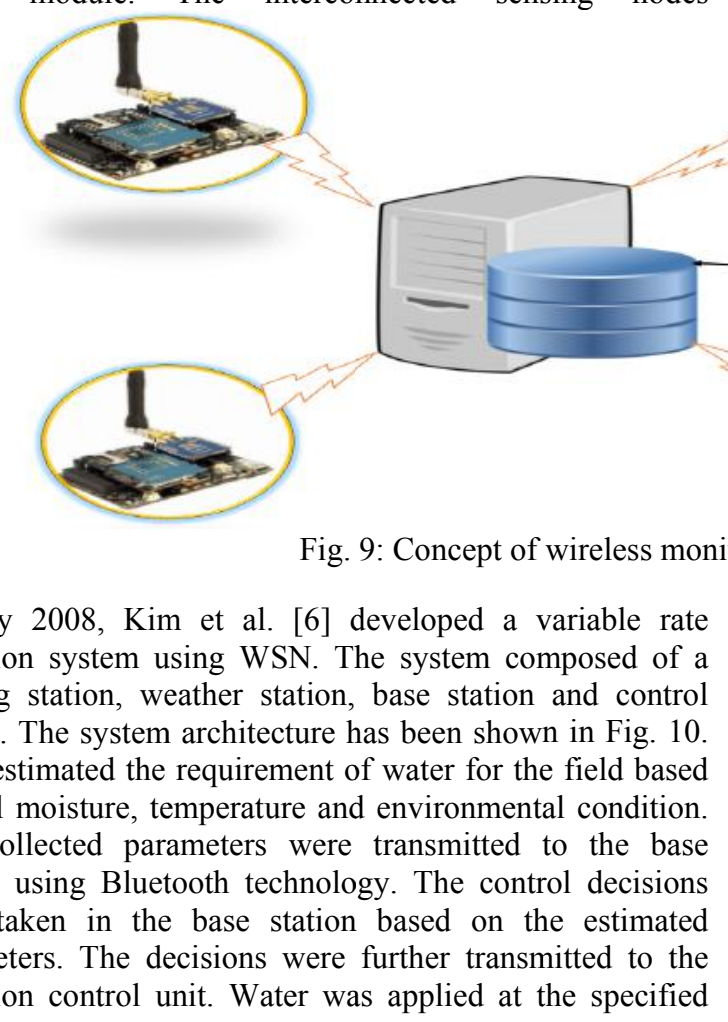

In July 2008, Kim et al. [6] developed a variable rate irrigation system using WSN. The system composed of a sensing station, weather station, base station and control station. The system architecture has been shown in Fig. 10. They estimated the requirement of water for the field based on soil moisture, temperature and environmental condition. The collected parameters were transmitted to the base station using Bluetooth technology. The control decisions were taken in the base station based on the estimated parameters. The decisions were further transmitted to the irrigation control unit. Water was applied at the specified transmitted analogue data to the center hub. The central server stored the data so that the farmers can access the data for analysis as per the requirement. Along with other factors, the module senses temperature and humidity. However, it has some limitations. Since the module is WSN802G Wi-Fi / 802.11, the power consumption is higher than other wireless modules. Moreover, it has some security issues due to which data can get corrupted during transmission.

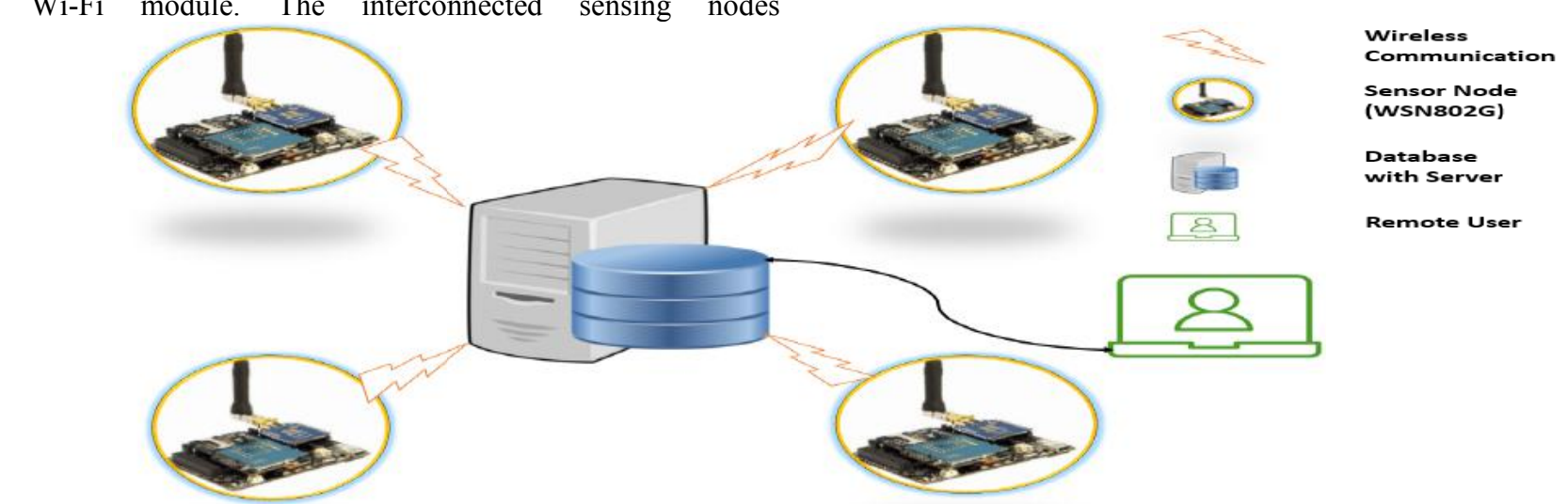

position through the sprinkler. The system used Bluetooth technology to transmit data and control decision. Thus, it helped in the precise management with increased productivity, reducing the environmental pollution. The system has some limitation like slow data speeds, low transmission range, poor data security and shortened battery life. In addition to that, a large number of nodes are required to cover the field area, as the range of Bluetooth is very low. But, this large number of nodes may create interference which can cause noise and overlapped data. 


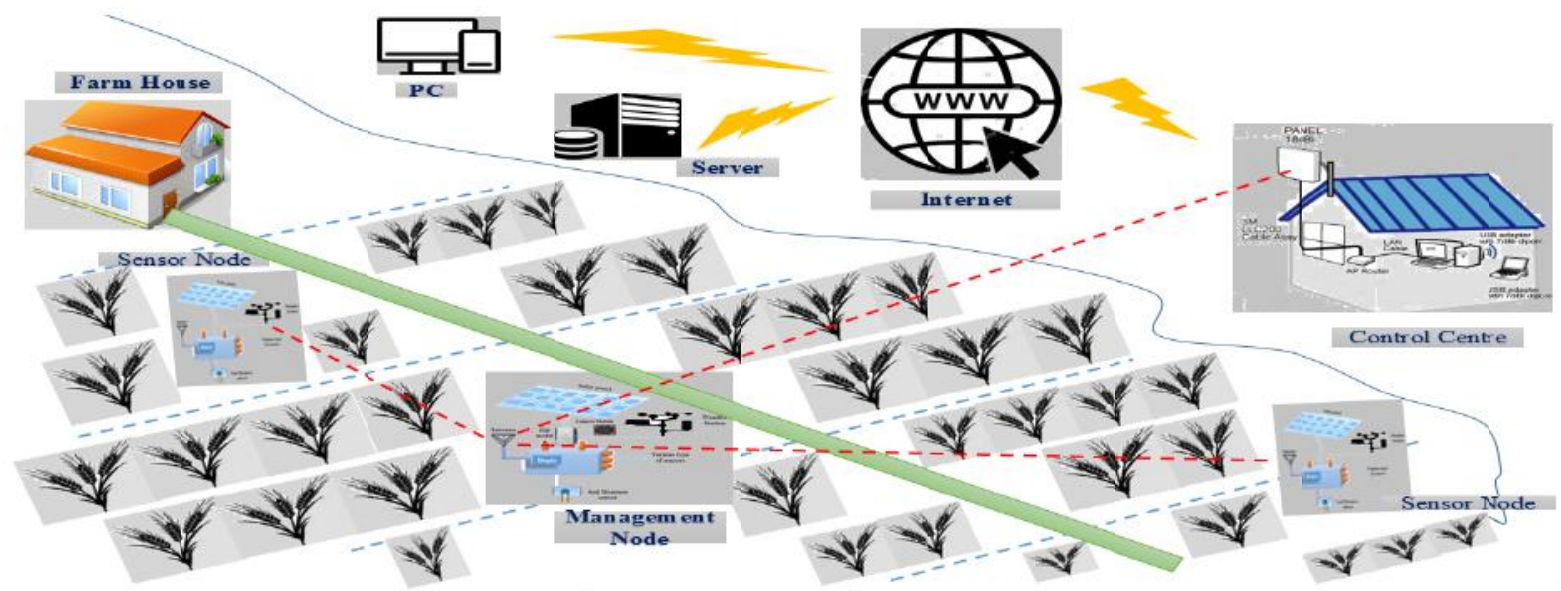

Fig. 10: Conceptual system layout of in-field wireless sensor network for site-specific irrigation [6]

Verma et al. [7] proposed a field condition monitoring system based on WSN. The system architecture has been shown in Fig. 11. The system observed the humidity, temperature and light intensity understand the requirement of the crop field. It's composed of sensing module, RF unit and a computing unit. The sensing module sent the collected data to the computing unit through the XBee RF module.
The observed parameters were stored in the computing unit. The farmers could access this information through a graphical user interface loaded into the system. The system provided a high range of communication with a costly XBee radio frequency module. In addition, the system has some limitations - it cannot analyze the data and take control decision about the field parameters.

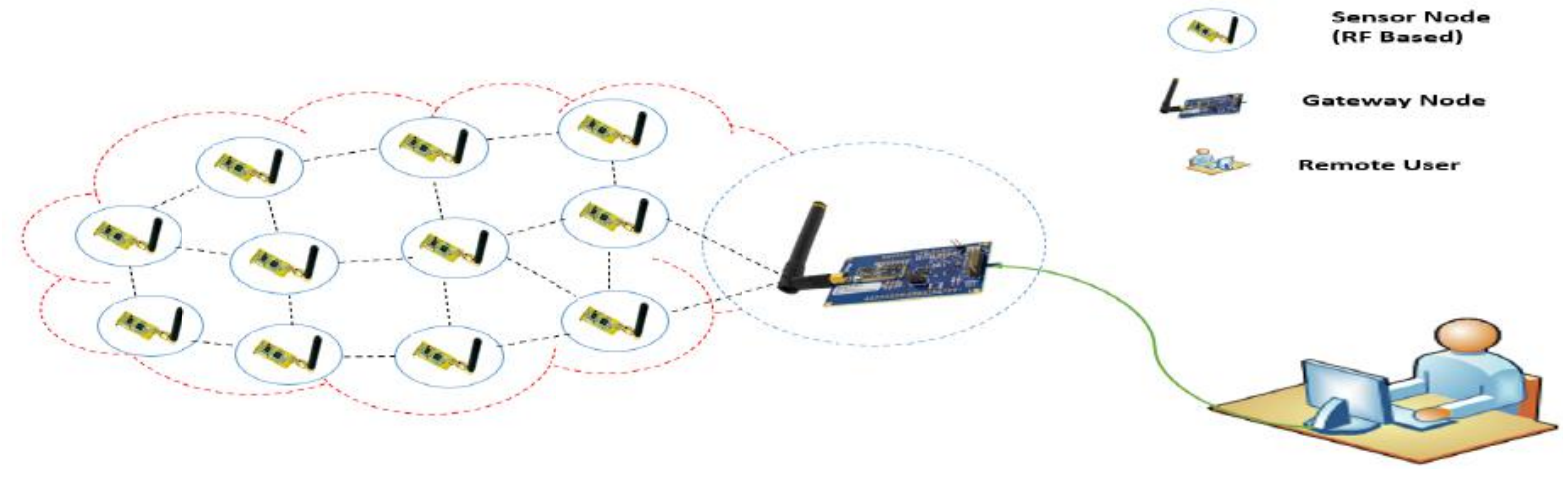

Fig. 11: Wireless Sensor Network for Crop Field Monitoring [7]

In 2011, K.Nirmal et al. [8] designed a real time automated crop monitoring system to monitor paddy crop field. The system gathered $\mathrm{pH}$, humidity, and temperature and moisture data and transferred it to the server for further processing. ZigBee technology was used for data transmission. An alarm was generated based on the threshold value set for each parameter in the server. The farmers were notified about the field condition through this alarm system. The order of the transmission was affected due to the packet loss, as the system could not re-transmit the data packet. The replacement cost of this system is high as it uses costly Zigbee technology.

Sarika et al. [9] proposed a Downy Mildew disease detection system for the grape field based on the environmental temperature, humidity and wind speed using wireless sensor network. The system architecture of the proposed model is given in Fig. 12. The system detected the disease based on environmental parameters only. The plant health and field condition were not observed in the system. These two parameters are highly correlated. But the authors did not consider these parameters. This system did not provide a precise solution for the disease control as it detected the disease after the appearance of the visual symptoms. 


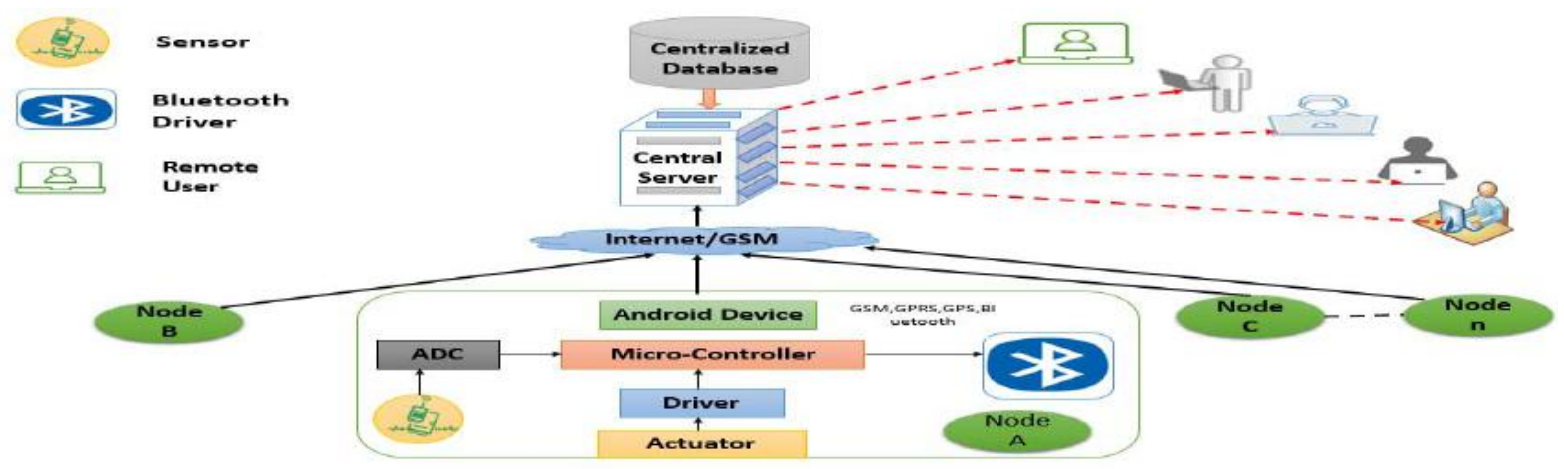

Fig. 12: Layout for Monitoring and Detection of Agricultural Disease using Wireless Sensor Network [9]

Mat et al. [10] designed an irrigation control unit using WSN based on soil moisture level. In this system, Wireless Moisture Sensor Network (WMSN) technology was used to monitor and control the moisture level of the field to enhance the crop productivity. However, they did not consider environmental and field parameters, which may affect the water requirement of the field. The architecture of the system is shown in Fig. 13.

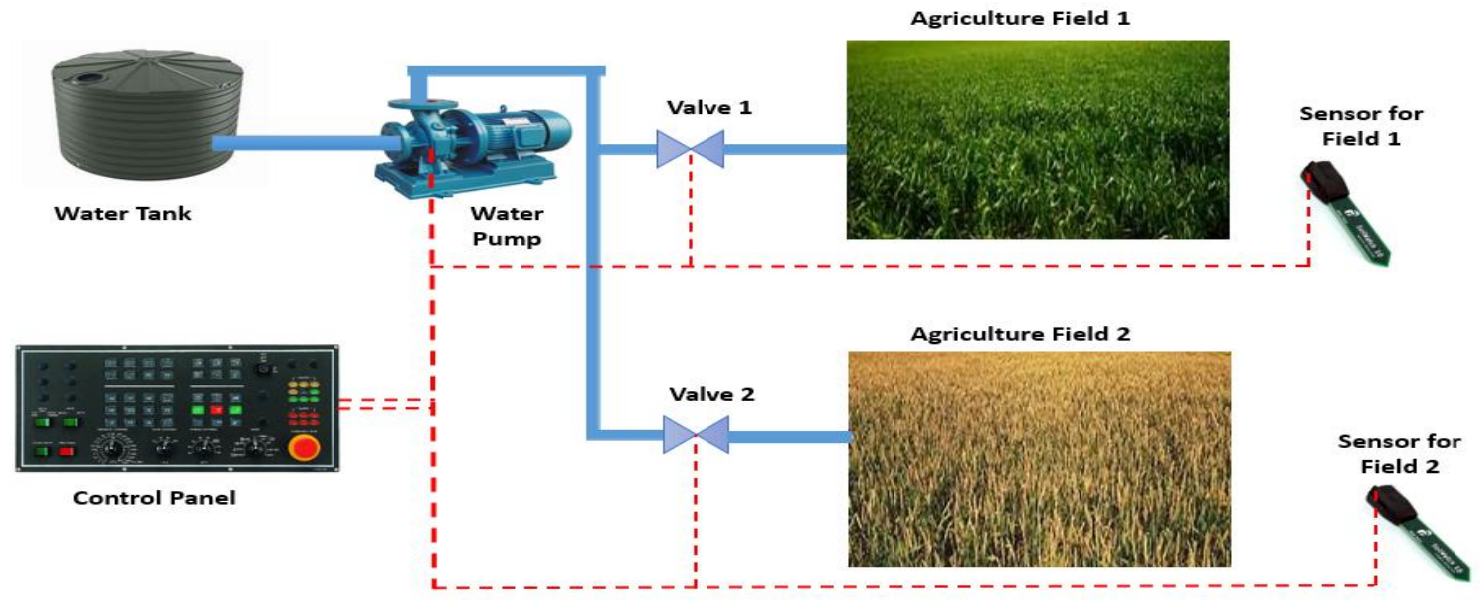

Fig. 13: Irrigation Control system using WSN [10]

In 2013, Bang et al. [11] proposed a deployment model of WSN for PA application. The recommended model used very simple geometric relation between a sensor and its neighboring space points. The sensors were deployed based on their range and the degree of connectivity. This model also helped with energy efficient data collection by providing efficient information coverage. However, this system did not use any scheduling algorithm for the sensing module. It causes noisy data and high-power consumption.

Das et al. [12] designed an automated monitoring system consisting of sensors, camera, GPS device pivoted on an unmanned aerial vehicle (UAV). This system extracted crop related information like canopy volume, morphological pattern, and yield and leaf area index from this system. The system was fixed at a particular angle. Thus, to cover the variability of the whole field, the system needs to be modified accordingly. A block diagram of this system is presented in Fig. 14. The system first collected position of data fromthe collection point through GPS receiver. This positional data was cleaned with an extended Kalman filter to extract useful positional data. Then thermal and spectral images of the field were collected. These images were further mapped with the positional information through GIS software. A 3D map was generated in GIS software with this information. Further, a predictive model was developed from this mapped data to assess the canopy volume, water stress, leaf area, fruit count etc. 


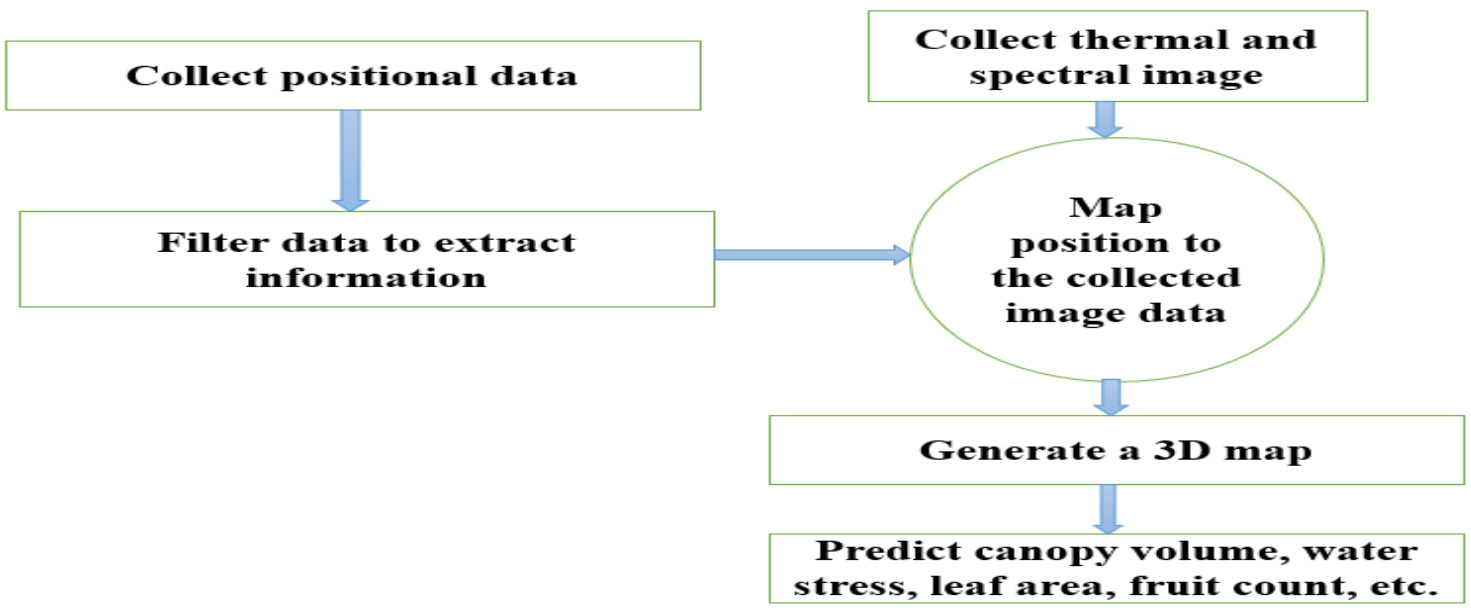

Fig. 14: The data processing pipeline starts with the WSN [12]

In 2015, Pascual et al. [13] proposed a model, which could monitor temperature, relative humidity and soil moisture wirelessly using ZigBee protocol. Data were collected in a remote computing unit through XBee. The data were analyzed in MATLAB software. The system architecture
(Fig. 15) consisted of soil moisture, humidity and temperature sensor, XBee unit and Arduino. But, one main drawback of the system is its use of the costly transmission device

(XBee).

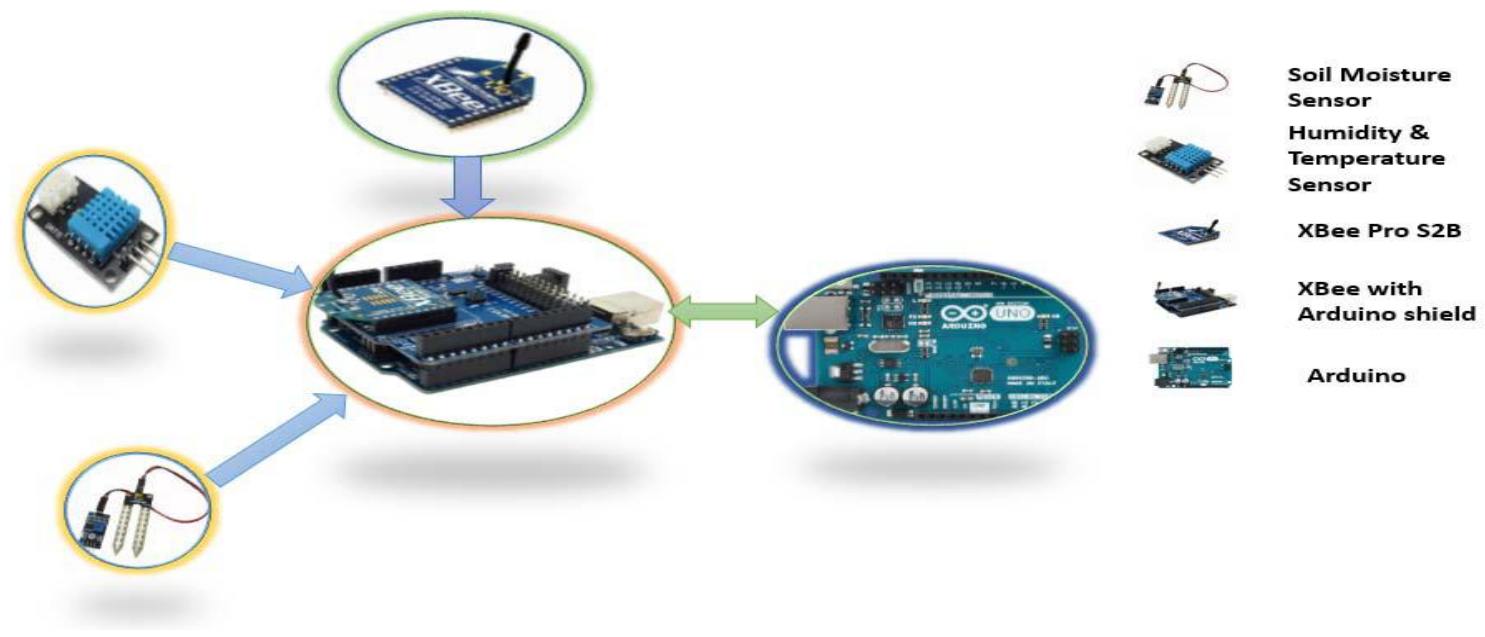

Fig. 15: Sensor Node Block Diagram for Precision Agriculture [13]

Maurya et al. [14] proposed an energy efficient routing protocol to maximize the lifetime of the sensor network. Sensor nodes continuously sense temperature and soil moisture content of agricultural field and check whether the value of these parameters exceeds the desired threshold level or not. If the value exceeds the limit, then a data packet will be sent to the base station. Control decisions are taken based on the reception of this data packet. Thus, the system reduces the continuous transmission and consequently the power consumption for communication. The limitation of the proposed protocol is that the base station stays idle in case the sensed value does not cross the threshold value for the parameters.

In 2015, Mr. Gaikwad S. V. et al. [15] proposed a monitoring system using WSN to observe environmental parameters like NPK, temperature and Humidity, etc. The system lacks in generating control decisions for field condition. The given Fig. 16explains the architecture. 


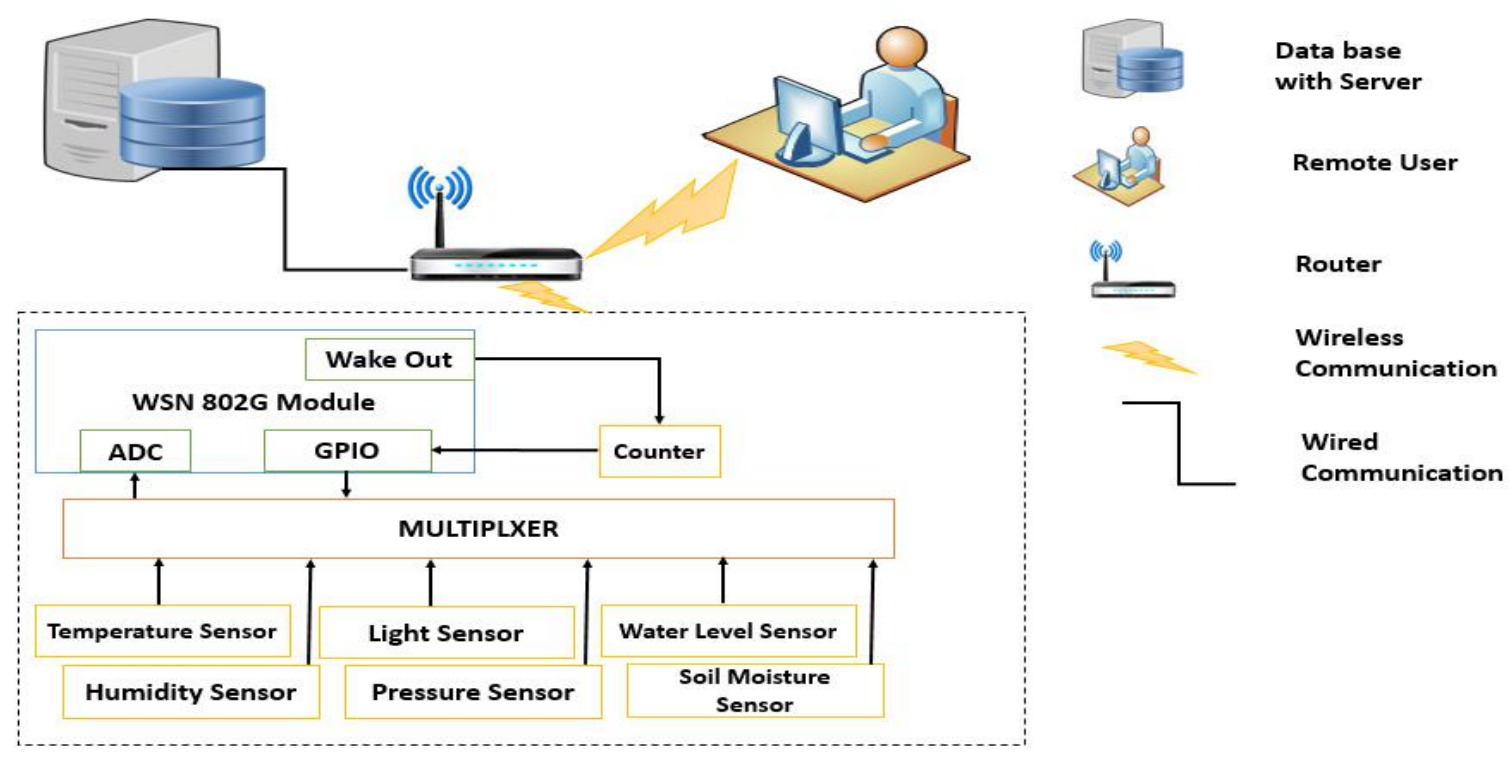

Fig. 16: Functional block diagram of monitoring system [15]

The reviewed articles are summarized in Table 3 with the proposed schemes and their drawbacks.

Table 3: Summary of the Literature Review

\begin{tabular}{|c|c|c|}
\hline Paper & System & Drawbacks \\
\hline [6] & Variable rate irrigation using Bluetooth & $\begin{array}{l}\text { Data overlapping, low transmission range, not secure as } \\
\text { unlicensed band is used for data transmission }\end{array}$ \\
\hline [7] & Field parameter monitoring system & System cannot analyze data to control field parameters \\
\hline [8] & Paddy crop and fieldmonitoring system & No mechanism to resend the lost packet \\
\hline [1] & $\begin{array}{l}\text { Wi-Fi based sensing module to collect } \\
\text { environmental and field data. }\end{array}$ & High Power consumption \\
\hline [9] & Disease detection and monitoring system & Only disease detection but no control mechanism \\
\hline$[10]$ & $\begin{array}{l}\text { Irrigation control system by using } \\
\text { Wireless Moisture Sensor Network } \\
\text { (WMSN) Technology }\end{array}$ & $\begin{array}{l}\text { No other environmental and field parameters are considered } \\
\text { except soil moisture level }\end{array}$ \\
\hline$[11]$ & $\begin{array}{l}\text { A geometric relation between a sensor } \\
\text { and its surrounding space points }\end{array}$ & $\begin{array}{l}\text { No information about deployment strategy and scheduling } \\
\text { algorithm }\end{array}$ \\
\hline$[12]$ & Automated monitoring system & $\begin{array}{l}\text { Device fixed at a particular angle and distance thus lacks in } \\
\text { monitoring the crop from other sides }\end{array}$ \\
\hline [13] & $\begin{array}{l}\text { Field \& environmental parameters } \\
\text { monitoring and controlling system }\end{array}$ & $\begin{array}{l}\text { Since the model used XBee for communication, the system } \\
\text { is not cost effective }\end{array}$ \\
\hline$[14]$ & $\begin{array}{l}\text { An energy efficient network layer routing } \\
\text { protocol }\end{array}$ & $\begin{array}{l}\text { Base station cannot retrieve any data until the values of } \\
\text { parameters cross the threshold level. As a result, base } \\
\text { station remains idle for a long time }\end{array}$ \\
\hline$[15]$ & $\begin{array}{l}\text { Monitoring system to notice the } \\
\text { environmental and field parameters. }\end{array}$ & $\begin{array}{c}\text { System only observed and stored the parameters and did not } \\
\text { provide any control decision }\end{array}$ \\
\hline
\end{tabular}

\section{CLASSIFICATION OF EXISTING SYSTEM}

The literatures can be classified according to the design of experiments. There are two types of study found in literature, one is simulation based system and another is an implementation based system. Simulation based system can be further divided into three classes according to the type of simulator. Implementation based system is also classified into three classes. The given figure (Fig.17) represents these classifications of WSN applied in PA. 


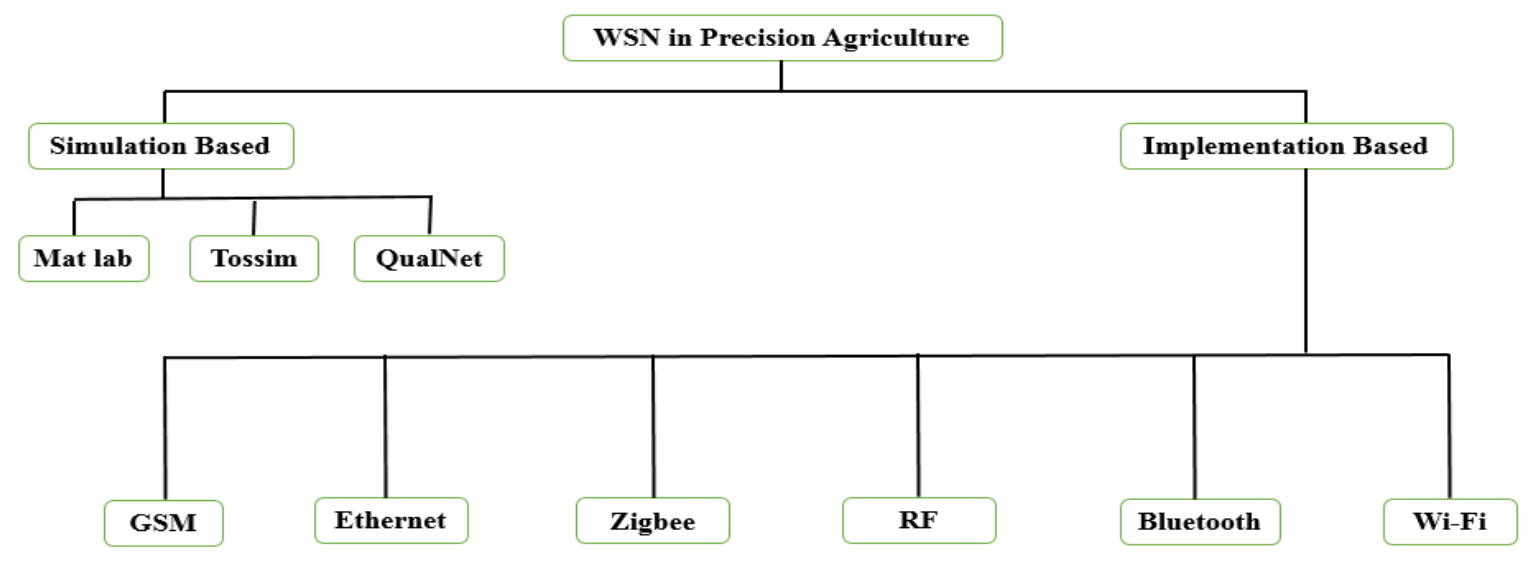

Fig. 17: Classification of Existing System

In [13] the authors proposed a simulation based WSN for PA application. They used MATLAB 7.0 software for the simulation. In [28] the authors implemented a WSN for energy efficient data transmission among sensor nodes using the Tossim simulation tool. In [29] the authors proposed a simulation based WSN for PA application. They used theQualNet software for the simulation.

In [22] the authors implemented a WSN for collecting data and monitoring the field parameters using GSM and ubiquitous wireless sensor networks. In [7] the authors proposed an implementation based WSN for PA application. They used Ethernet with Radio Frequency for implementing the project in real life. In $[23,27]$ the authors implemented a WSN for soil moisture monitoring system in the field usingZigbee. In $[21,26]$ the authors proposed an

\section{COMPARISON STUDY OF REVIEWED ARTICLES}

The existing WSN approaches are compared in Table 4 based on their applications, characteristics, schemes, technology and drawbacks. Table 3 represents the papers with their proposed schemes and existing drawbacks in their system. Table 4 compares the reviewed articles based on their technical details. From the table, we can observe that WSN is applied in PA for irrigation control, crop monitoring, field \&environmental parameter monitoring system etc. The major contributions of the reviewed literatures are classified based on their proposed system, technology, sensors, frequency band, range of communication, battery life, cost and power consumption. The limitation of each study is described in the "Remarks" column.

In the crop monitoring system proposed in [1, 23, 27] soil moisture, temperature, wind speed, wind direction, humidity, rain gauge, water and $\mathrm{pH}$ sensors were used. The sensor nodes communicated with each other and transmitted the data to the gateway through the Zigbee technology. Whereas in case of real time monitoring system $[18,25,28]$ although the same type of sensors was used but data implementation based WSN for PA application. They used Radio Frequency for the automated irrigation control system. In [3,5,11,22,24,25] the authors implemented a WSN for environmental parameter monitoring and data collection system in the field using Bluetooth. In [25, 28] the authors proposed an implementation based WSN for PA application. They used Wi-Fi for controlling the water level of the field.

This analysis helps to figure out the most frequently used hardware for PA applications. Bluetooth with Ethernet is the most common combination used in the reviewed literatures for data collection. RF with Ethernet module are used very rarely in these articles. The cost of RF module is lower than all other modules, so RF with Ethernet can be a costeffective solution for future application.

transmission was done through the Wi-Fi technology. Due to the use of Wi-Fi, the module supports easy configuration and communication among deployment nodes. This technology also provides secure data transmission. But the power consumption is comparatively higher than other technology-based systems. Therefore, it is not suitable for covering large area with a significantly high number of nodes. On the other hand, although Zigbee technology provides secure data transmission with low power consumption, but it causes high cost. To provide the costeffective module, Bluetooth technology is used [22, 24] in monitoring and data collection system. This technology is used with all types of major sensors as it is cost effective and requires low power consumption. The major drawbacks of these systems are low communication range and data overlapping. To overcome low communication range, RF technology was introduced in the automated irrigation control system [21, 26] for controlling the soil moisture. However, it also suffers from the reconfiguration problem while adding new nodes.

Thus, it can be noticed that each technology-based system suffers from certain types of problems. None of these systems offer completes solution with respect to costand communication range and power consumption. Consequently, there is immense research scope to design a 
secure automated monitoring and controlling system considering all spatial and temporal variables involved in agricultural pursuit. Further research is also required to find the applicability of low-cost LORA technology in PA, to overcome the power consumption problem and low communication range.
From this comparison, we can conclude that a low cost WSN with extended lifetime is required to monitor spatial and temporal variables and their interdependency

Table 4: Comparison Table for Reviewed Articles

\begin{tabular}{|c|c|c|c|c|c|c|c|c|c|}
\hline Ref & Sys & Tech & Sensor & Freq & Range & Battery & Cost & Power & Remarks \\
\hline$[1]$ & $\begin{array}{c}\text { Crop } \\
\text { Monitori } \\
\text { ng } \\
\text { System }\end{array}$ & ZigBee & $\begin{array}{c}\text { Soil } \\
\text { moisture/ } \\
\text { temperature, } \\
\text { Wind speed, } \\
\text { wind } \\
\text { direction, } \\
\text { temperature, } \\
\text { humidity, } \\
\text { rain gauge, } \\
\text { water and } \\
\text { pH level }\end{array}$ & $\begin{array}{c}68 \\
\mathrm{MHz} \\
902- \\
928 \\
\mathrm{MHz} \\
2.4 \\
\mathrm{GHz}\end{array}$ & $\begin{array}{c}100- \\
200 \mathrm{~m}\end{array}$ & $\begin{array}{c}\text { Greater } \\
\text { than one } \\
\text { year }\end{array}$ & High & Low & $\begin{array}{c}\text { Data } \\
\text { Conflict in } \\
\text { communicati } \\
\text { on between } \\
\text { ZigBee and } \\
\text { Gateway due } \\
\text { to large } \\
\text { number of } \\
\text { nodes }\end{array}$ \\
\hline [18] & $\begin{array}{c}\text { Real time } \\
\text { monitori } \\
\text { ng } \\
\text { system }\end{array}$ & Wi-Fi & $\begin{array}{c}\text { Temperature } \\
\text {, humidity, } \\
\text { water level, } \\
\text { soil } \\
\text { moisture, } \\
\text { light, and } \\
\text { pressure. }\end{array}$ & $\begin{array}{c}2.4 \\
\mathrm{GHz}\end{array}$ & $100 \mathrm{~m}$ & $2-3 \mathrm{hrs}$ & Low & High & $\begin{array}{c}\text { Short battery } \\
\text { life. }\end{array}$ \\
\hline [21] & $\begin{array}{c}\text { Node } \\
\text { deploym } \\
\text { ent in } \\
\text { WSN }\end{array}$ & $\begin{array}{c}\text { Radio } \\
\text { Frequenc } \\
\text { y }\end{array}$ & $\begin{array}{c}\text { Soil } \\
\text { moisture }\end{array}$ & $\begin{array}{l}315, \\
433, \\
868, \\
915 \\
\mathrm{MHz}\end{array}$ & $150 \mathrm{~m}$ & $\begin{array}{c}\text { 6-12 } \\
\text { months }\end{array}$ & Low & Low & $\begin{array}{c}\text { Reconfigurat } \\
\text { ion Problem } \\
\text { with adding } \\
\text { new node }\end{array}$ \\
\hline$[22]$ & $\begin{array}{l}\text { Monitori } \\
\text { ng and } \\
\text { data } \\
\text { collectio } \\
\text { n system }\end{array}$ & $\begin{array}{c}\text { Bluetoot } \\
\mathrm{h}\end{array}$ & $\begin{array}{c}\text { Air } \\
\text { temperature, } \\
\text { wind } \\
\text { speed/directi } \\
\text { on, air } \\
\text { humidity, air } \\
\text { pressure }\end{array}$ & $\begin{array}{c}2.4 \\
\mathrm{GHz}\end{array}$ & $10 \mathrm{~m}$ & 1 Week & Low & Low & $\begin{array}{l}\text { Short range } \\
\text { communicati } \\
\text { on and data } \\
\text { overlapping }\end{array}$ \\
\hline [23] & $\begin{array}{c}\text { Soil } \\
\text { moisture } \\
\text { monitori } \\
\text { ng } \\
\text { system }\end{array}$ & Zigbee & $\begin{array}{c}\text { Temperature } \\
\text { Humidity }\end{array}$ & $\begin{array}{c}68 \\
\mathrm{MHz} \\
902- \\
928 \\
\mathrm{MHz} \\
2.4 \\
\mathrm{GHz}\end{array}$ & $\begin{array}{c}100- \\
200 \mathrm{~m}\end{array}$ & $>1 \mathrm{yr}$ & High & Low & $\begin{array}{c}\text { Soil and } \\
\text { crop } \\
\text { Parameters } \\
\text { are not } \\
\text { monitored }\end{array}$ \\
\hline [24] & $\begin{array}{l}\text { Agricultu } \\
\text { re } \\
\text { environm } \\
\text { ent } \\
\text { monitori } \\
\text { ng } \\
\text { system }\end{array}$ & $\begin{array}{c}\text { Bluetoot } \\
\mathrm{h}\end{array}$ & $\begin{array}{c}\text { Temperature } \\
\text {, } \\
\text { Relative, } \\
\text { Humidity, } \\
\text { Soil } \\
\text { Moisture } \\
\text { PH, } \\
\text { Light }\end{array}$ & $\begin{array}{c}2.4 \\
\mathrm{GHz}\end{array}$ & $10 \mathrm{~m}$ & 1 Week & Low & Low & $\begin{array}{l}\text { Since its } \\
\text { communicati } \\
\text { on range is } \\
\text { low, it can } \\
\text { be used in } \\
\text { greenhouse } \\
\text { application. }\end{array}$ \\
\hline
\end{tabular}




\begin{tabular}{|c|c|c|c|c|c|c|c|c|c|}
\hline [25] & $\begin{array}{c}\text { Crop } \\
\text { monitori } \\
\text { ng } \\
\text { system }\end{array}$ & Wi-Fi & $\begin{array}{c}\text { Temperature } \\
\text { Humidity, } \\
\text { Pressure, } \\
\text { Soil } \\
\text { Moisture, } \\
\text { PH }\end{array}$ & $\begin{array}{c}2.4 \\
\mathrm{GHz}\end{array}$ & $100 \mathrm{~m}$ & $2-3 \mathrm{hrs}$ & Low & High & $\begin{array}{l}\text { The module } \\
\text { supports } \\
\text { easy } \\
\text { configuratio } \\
\text { nandcommu } \\
\text { nication } \\
\text { among the } \\
\text { deployed } \\
\text { nodes }\end{array}$ \\
\hline [26] & $\begin{array}{l}\text { Automat } \\
\text { ed } \\
\text { irrigation } \\
\text { control } \\
\text { system }\end{array}$ & $\mathrm{RF}$ & $\begin{array}{c}\text { Temperature } \\
\text { Moisture }\end{array}$ & $\begin{array}{c}315, \\
433, \\
868, \\
915 \\
\mathrm{MHz}\end{array}$ & $150 \mathrm{~m}$ & $\begin{array}{c}\text { 6-12 } \\
\text { months }\end{array}$ & Low & Low & $\begin{array}{l}\text { Field and } \\
\text { crop } \\
\text { parameters } \\
\text { are not } \\
\text { considered }\end{array}$ \\
\hline [27] & $\begin{array}{c}\text { Real time } \\
\text { monitori } \\
\text { ng } \\
\text { system }\end{array}$ & Zigbee & $\begin{array}{c}\text { Temperature } \\
\text { Humidity, } \\
\text { Gas }\end{array}$ & $\begin{array}{c}68 \\
\mathrm{MHz} \\
902- \\
928 \\
\mathrm{MHz} \\
2.4 \\
\mathrm{GHz}\end{array}$ & $\begin{array}{c}100- \\
200 \mathrm{~m}\end{array}$ & $\begin{array}{l}\text { Greater } \\
\text { than year }\end{array}$ & High & Low & $\begin{array}{c}\text { It saves } \\
\text { energy and } \\
\text { provides } \\
\text { secure } \\
\text { communicati } \\
\text { on }\end{array}$ \\
\hline [28] & $\begin{array}{c}\text { Data } \\
\text { collectio } \\
\text { n system }\end{array}$ & Wi-Fi & $\begin{array}{c}\text { Water level, } \\
\text { Soil } \\
\text { moisture }\end{array}$ & $\begin{array}{c}2.4 \\
\mathrm{GHz}\end{array}$ & $100 \mathrm{~m}$ & $1-2 \mathrm{hrs}$ & Low & High & $\begin{array}{l}\text { The system } \\
\text { is not } \\
\text { effective for } \\
\text { large scale } \\
\text { farming due } \\
\text { to high } \\
\text { power } \\
\text { consumption }\end{array}$ \\
\hline
\end{tabular}

Fig. 18 compares the wireless communication technologies considered in reviewing literatures with respect to consumed power, communication range and cost. From these graphs, it is clear that Bluetooth is a low powered and low-cost technology used in PA application. But, the disadvantage of transmitting at unlicensed band and lower communication range in Bluetooth encourages the researcher to use, low cost, low power consumption and long-range LORA module. With these comparisons it is clear that RF module is the most profitable technology used in PA application with respect to cost, power consumption and communication range.

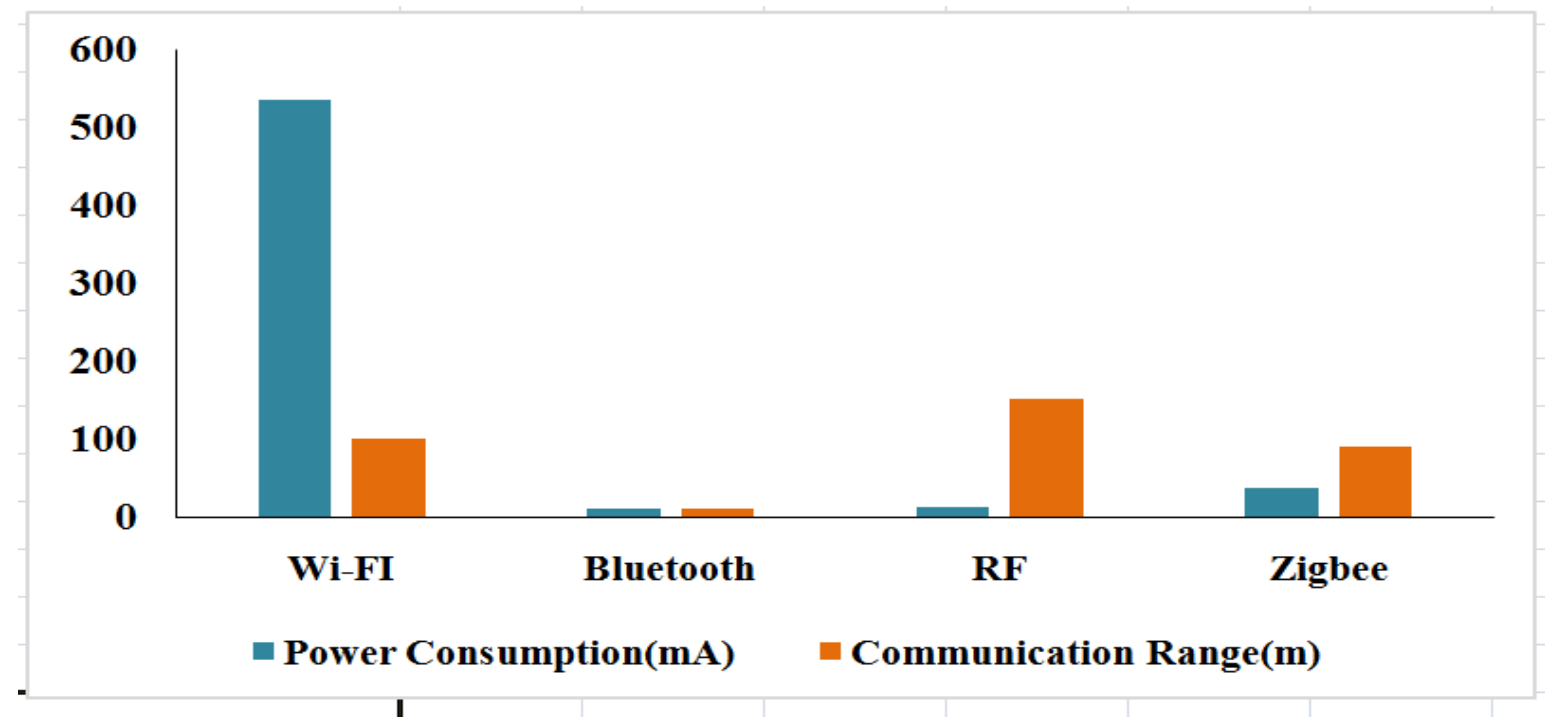

(a) 


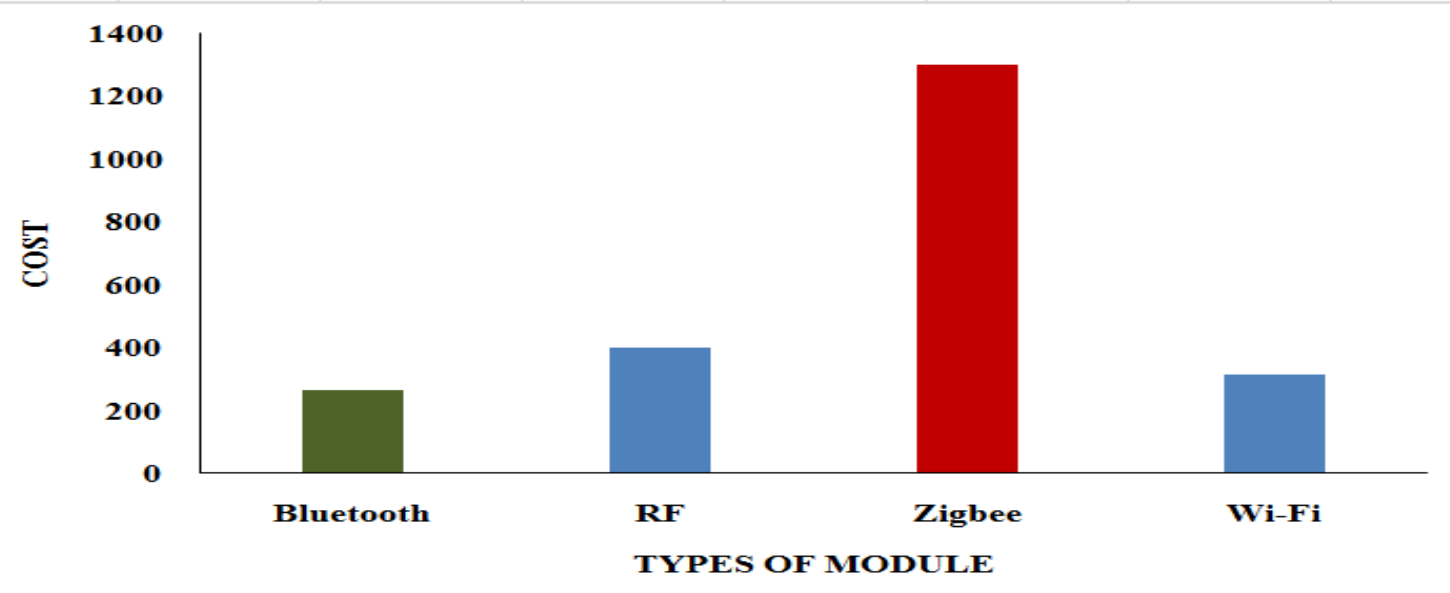

(b)

Fig. 18: Comparison of Wireless Communication Technologies: (a) Comparison with respect to Power Consumption and Communication Range, (b) Comparison with respect to Cost

\section{CHALLENGES OF SENSOR BASED MONITORING IN PA}

The development of WSN initiates new research movements in the Precision Agricultural domain. WSN with tiny, selfcontrolling sensor nodes, low cost equipment, and scalability makes it suitable for agricultural automation. However, there are several open issues related to the deployment of WSN that makes this automation a challenging task. Some of these challenges are listed below.

\subsection{Power Consumption and Battery Life}

The time required from sowing to harvesting is 3-4 months. The system of WSN needs to be sustained throughout this period for real time monitoring. During these periods, frequent battery replacement is not feasible and cost effective. Therefore, power consumption of the sensor network must be low to ensure extended battery life. Hence, high performance battery or renewable energy source such as small solar panels, rechargeable battery etc. is required. In case of multi-hop WSN the rate of power consumption is increased due to the large number of communication links. Therefore, new schemes must be developed to optimize the power consumption in order to increase the overall network lifetime.

\subsection{Communication Range}

WSN may suffer from several natural calamities due to the large field surroundings in the open air. In agricultural applications, most wireless sensor technologies support a relatively short communication range. Therefore, many sensors and router nodes need to be spread in a field. In the point-to-point WSN, the communication distance can reach $100 \mathrm{~m}$ in outdoor environments. The WSN communication range can be extended by adopting multi-tire, ad-hoc, decentralized, and mesh network topologies. Drones or UAV also can be used as a mobile router node to extend the communication range within a farm field. A drone can pass the collected data from the sensor nodes to the master node in multi-hop manner. However, using drones involves other challenges and limitations like cost, battery life. Security etc. A good and effective system with high range communication requires algorithms to control error in transmitted data.

\subsection{Deployment}

Deployment means placing the actual sensors in a realworld environment. Proper deployment of the sensors is a critical area that needs to be addressed with proper care in order to increase network lifetime, reduce communication cost and communication delay and increase the overall effectiveness of the network. The system can be implemented using star topology with single-hop communication. The system architecture consists of base station and PC, as a server. The server can monitor and display the data. For large deployment of huge numbers of nodes, cluster tree based multi-hop communication may be more appropriate which needs further investigation.

\subsection{Localization}

The important function of a sensor network is to retrieve and forward data to the destination node. In real time, sensors are deployed from the airborne system without knowing the actual position in remote places. There may be no supporting transportation to reach that position. In this scenario, physical locations of the sensors need to be determined by localization algorithm. Hence, effective localization technique is required for the WSN.

\subsection{Synchronization}

In case of wireless networks, synchronization is very important for basic communication. The synchronization related problem depends upon the four parts: send time, access time, propagation time, and receive time. In agriculture environment, clock synchronization is required for analyzing the data and participating in the monitoring system to take correct control decision at right time.

\subsection{Security}

Security is essential for reliable data transmission. Sometimes data retrieved from the sensors cannot be transmitted to the base station in its original form. During 
transmission, some error can be generated or mixed up with the original data. To protect the data from various malicious activities, certain security issues need to be carefully handled.

\subsubsection{Data Integrity}

It ensures that data packets are correctly transferred from the sender to the destination and cannot be changed in the middle. It ensures the assurance of the accuracy and consistency of data over its entire life-cycle. This problem may be solved by using secure tunnel through VPN functionality.

\subsubsection{Data Confidentiality}

Confidentiality is the specific mechanism to ensure the protection of data from harmful intruders. It allows only the authorized users to access sensitive and protected data. During short- or long-range communication over the medium, confidentiality is one of the most important issues in network security which can be solved by the application of appropriate cryptographic mechanisms.

\subsubsection{Data Authentication}

Without proper authentication, the data may be hijacked, accessed or changed by any unauthorized person or authority. This problem may be solved by using a secret key to compute a message authentication code for all communicated data.

\subsection{Real time}

The health of crops and yield depends on climate conditions, like humidity, intensity of illumination, temperature, etc. Monitoring the weather conditions in hourly or daily basis are very laborious to the farmers. For these reasons, WSN deployed in the field needs to be activated at a particular time gap for real time monitoring of the spatial and temporal variability of the agricultural field. Thus, real-time monitoring systems need to be developed to enhance the crop productivity and plant growth and avoid disasters in farms.

\subsection{Cost}

The important part of designing WSN infield is the hardware and software cost. The sensor node designed for any agricultural application needs to be cost effective so that the farmers can easily afford it. The design cost of the module should be decided according to the country market. So designing a cost effective WSN is really a challenging task.

\subsection{Storage \&Data Management}

The data management is an important part of PA. The large amount of data collected from several sensors in agricultural field needs to be stored for further analysis which is a challenging job. The modern cloud environment may serve this requirement for a high volume of storage in an efficient manner. The researcher should also pay attention to the (i) data collection schemes, (ii) data analysis method, (iii) sensor types, (iv) semantic sensor networking, (v) big data, and (vi) complex event processing for effective data management. The integration of IoT and software-defined network holds a huge promise for an efficient new methodology involving the deployment, monitoring, and designing of a WSN.

\section{CONCLUSION}

This survey provides a useful insight into the applications, topology, communication technologies and protocols of WSN used in PA. WSN based PA is helpful for farmers to enhance the productivity and quality. It is more applicable than the traditional agricultural practice. The wireless monitoring and control improve the effectiveness and efficiency of resources used, which leads to the sustainable development. Wide ranges of sensors are available in the market, which are useful in the field of agriculture. With the introduction of the wireless sensor network, we can accumulate the data in the gateway and can process it to obtain some meaningful results with the help of these sensors. This survey helps to find out the type of sensors used in PA, topology to deploy the sensors over the field and communication technology for data transmission. The reviewed literatures are compared with respect to their key findings to figure out the future research areas. The challenges that need to be addressed for an effective PA application are also discussed in this survey.

\section{FUTURE SCOPE}

Data collection, management and control of resources, maintaining inter-dependability among spatial-temporal variability using wireless sensor network is a challenging task. From the literature review, it is clear that no literature considers all the major types of variability's in the field and environment. Therefore, there is immense research scope to design a secure automated monitoring and controlling system considering all spatial and temporal variables involved in agricultural pursuit. Further research is also required to find the applicability of low-cost LORA technology in $\mathrm{PA}$, to overcome the power consumption problem and low communication range.

\section{REFERENCES}

[1] G. R. Mendez, M. A. M. YunusandS. C. Mukhopadhyay, "A WiFi based smart wireless sensor network for monitoring an agricultural environment", In Instrumentation and Measurement Technology International Conference (I2MTC), IEEE, 2012, pp. 2640-2645.

[2] C. Arun, and K. Lakshmi Sudha, "Agricultural management using wireless sensor networks-A survey", In 2nd International Conference on Environment Science and Biotechnology (IPCBEE), Vol. 48(15), 2012.

[3] I. Mampentzidou ,E. Karapistoli, and A. Anastasios Economides, "Basic guidelines for deploying wireless sensor networks in agriculture", In Ultra Modern Telecommunications and Control Systems and Workshops (ICUMT), IEEE, 2012, pp. 864-869.

[4] M. Zhijun, Z. Chunjiang, W. Xiu, C. Liping, and X.Xuzhang,"Field multi-source information collection system based on GPS for precision agriculture", In Transactions of The Chinese Society of Agricultural Engineering,Vol. 4(2), 2003.

[5] F. El-Moukaddem, E. Torng and G. Xing, , "Mobile relay configuration in data-intensive wireless sensor networks" In IEEE Transactions on Mobile computing, Vol. 12(2), 2013, pp. 261-273. 
[6] Y. Kim, R. G., Evans, and W. M. Iversen, "Remote sensing and control of an irrigation system using a distributed wireless sensor network." IEEE transactions on instrumentation and measurement, Vol. 57(7), 2008, pp. 1379-1387.

[7] S. Verma, N. Chug, and D. V. Gadre, "Wireless sensor network for crop field monitoring", In Recent Trends in Information, Telecommunication and Computing (ITC), IEEE,2010, pp. 207-211.

[8] K.N. Kumar, P. Ranjith, and R. Prabakaran, "Real time paddy crop field monitoring using Zigbee network", In Emerging Trends in Electrical and Computer Technology (ICETECT), IEEE,2011, pp. 1136-1140.

[9] S. Datir, and S. Wagh, "Monitoring and Detection of Agricultural Disease use Wireless Sensor Network", In International Journal of Computer Applications, Vol. 87(4), 2014, pp. $1-5$.

[10] I. Mat, R.K.M. Mohamed, and N. H. Ahmad "Precision agriculture applications using wireless moisture sensor network", In 12th Malaysia International Conference on Communications (MICC), IEEE, 2015, pp. 777-780.

[11] B. Wang, X. Deng, W. Liu, L. T. Yang and H. C. Chao, "Confident information coverage in sensor networks for field reconstruction", In IEEE Wireless Communications, Vol. 20(6), 2013, pp. 74-81.

[12] J. Das, G. Cross, C. Qu, A. Makineni, P. Tokekar, Y. Mulgaonkar, and V. Kumar, "Devices, systems, and methods for automated monitoring enabling precision agriculture", In Automation Science and Engineering (CASE), IEEE,2015, pp. 462-469.

[13] R.L. Pascual, D.M.R.Sanchez, D.L.E. Naces, and W.A. Nunez, "A Wireless Sensor Network using XBee for precision agriculture of sweet potatoes (Ipomoea batatas)." Humanoid, Nanotechnology, Information Technology, Communication and Control, Environment and Management (HNICEM), IEEE,2015, pp.1-4.

[14] S. Mauryaand V. K. Jain, "Threshold sensitive region-based hybrid routing protocol for precision agriculture", In Wireless Communications and Networking Conference (WCNC), IEEE, 2016, pp.169-174.

[15] S. G. Galande, "Measurement of NPK, Temperature, Moisture, Humidity using WSN."InInternational Journal of Engineering Research and Applications (IJERA), Vol. 5(8), 2015, pp.84-89.

[16] P. Milindand P. C. Bhaskar, "Microcontroller Based Adaptive Irrigation System Using WSN for Variety Crops and Development of Insect Avoidance System for Better Yield", In International Journal of Research in Engineering and Technology (IJRET)Vol. 3(07), 2014, pp. 308-312.

[17] G. Deepika and P. Rajapirian, "Wireless sensor network in precision agriculture: A survey", In International Conference on Emerging Trends in Engineering, Technology and Science (ICETETS), IEEE, 2016, pp. 1-4.

[18] S. P. Goyal, and A. Bhise, "Zigbee Based Real-Time Monitoring System of Agricultural Environment." International Journal of Engineering Research and Applications, Vol. 4(2), 2014, pp. 06-09.

[19] M. Keshtgary and A. Deljoo, "An efficient wireless sensor network for precision agriculture." Canadian Journal on Multimedia and Wireless Networks, Vol. 3(1), 2012, pp.1-5.

[20] D. Ilie-Ablachim, G.C. Pătru, I.-M. Florea, D. Rosner, "Monitoring Device for Culture Substrate Growth Parameters for Precision Agriculture: Acronym: Monisen." In Proceedings of the 15th RoEduNet Conference: Networking in Education and Research,2016, pp. 1-7.
[21] M. Million, Z. Marco, B. Antoine, A. Graham, G. Harry, C.Timothy, "Successful deployment of a wireless sensor network for precision agriculture in Malawi.’InternationalJournal Distributed SensorNetwork,Vol. 9(5), 2013, pp. 150703.

[22] T.D. Nguyen, T.T. Thanh, L.-L.Nguyen, H.T. Huynh, "On the design of energy efficient environment monitoring station and data collection network based on ubiquitous wireless sensor networks." In Proceedings of the IEEE RIVF International Conference on Computing \& Communication Technologies Research, Innovation, and Vision for the Future (RIVF),2015, pp. 163-168.

[23] R. Zhang, L. Chen, J. Guo, Z.Meng, G. Xu, "An energyefficient wireless sensor network used for farmland soil moisture monitoring". In Proceedings of the IET Conference on Wireless Sensor Network, Beijing, China, 2010, pp. 2-6.

[24] Y. Tongtong, F. Wenjie, and L. Zheying, "Temperature and humidity wireless sensing and monitoring systems applied in greenhouse." IEEE International conference on computer science and network technology (ICCSNT), 2011, pp. 857861.

[25]Z. A. Shaikh, H. Yousuf, F.Nawaz, , M. Kirmani and S. Kiran, "Crop irrigation control using wireless sensor and actuator network (WSAN)." Information and Emerging Technologies (ICIET), International Conference on. IEEE, 2010, pp. 1-5.

[26] M. N. Sudha, M. L. Valarmathi, and A. S. Babu,"Energy efficient data transmission in automatic irrigation system using wireless sensor networks." Computers and Electronics in Agriculture, Vol. 78(2), 2011, pp.215-221.

[27] L. Gao, M. Zhang, and G. Chen, "An Intelligent Irrigation System Based on Wireless Sensor Network and Fuzzy Control." Journal of Networks (JNW), Vol. 8(5), 2013, pp.1080-1087.

[28] H. Sahota, R. Kumar, A. Kamal and J.Huang, "An energyefficient wireless sensor network for precision agriculture." Computers and Communications (ISCC),IEEE, 2010,pp. 347-350.

[29] A. F. Murillo, M. Peña and D. Martínez. "Applications of WSN in health and agriculture." Communications Conference (COLCOM), 2012 IEEE Colombian. IEEE, 2012.

[30] P.Baronti, P. Pillai, V. W. Chook, S. Chessa, A. Gotta and Y. F. Hu, "Wireless sensor networks: A survey on the state of the art and the 802.15. 4 and ZigBee standards." Computer communications, Vol. 30(7), 2017, pp.1655-1695.

[31]X. Peng and G. Liu. "Intelligent water-saving irrigation system based on fuzzy control and wireless sensor NETWORK." Digital In 2012 Fourth International Conference on Digital Home, IEEE, 2012, pp.252-256.

[32] G. Vellidis, M. Tucker, C. Perry, D. Reckford, C. Butts, H. Henry, V. Liakos, R. W. Hill, and W. Edwards"A soil moisture sensor-based variable rate irrigation scheduling system." Precision agriculture, 2013,pp.713-720.

[33] B. Majone, F. Viani, E. Filippi, A. Bellin, A. Massa, G. Toller, F. Robol, and M. Salucci,"Wireless sensor network deployment for monitoring soil moisture dynamics at the field scale." Procedia Environmental Sciences, Vol. 19, 2013, pp.426-435.

[34]H. Dubois-Ferriere, R.Meier, L. Fabreand P. Metrailler,'Tiny Node: a comprehensive platform for wireless sensor network applications." Information Processing in Sensor Networks, 2006.The Fifth International Conference on. IEEE, 2006, pp. 358-365. 